\title{
Elemental Geochemistry of Sedimentary Rocks at Yellowknife Bay, Gale Crater, Mars
}

S. M. McLennan ${ }^{1, *}$, R. B. Anderson ${ }^{2}$, J. F. Bell III ${ }^{3}$, J. C. Bridges ${ }^{4}$, F. Calef III ${ }^{5}$, J. L. Campbell ${ }^{6}$,

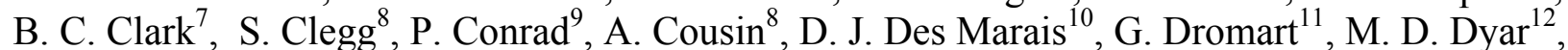
L. A. Edgar ${ }^{3}$, B. L. Ehlmann ${ }^{5,13}$, C. Fabre ${ }^{14}$, O. Forni ${ }^{15}$, O. Gasnault ${ }^{15}$, R. Gellert ${ }^{6}$, S. Gordon ${ }^{16}$, J. A. Grant ${ }^{17}$, J. P. Grotzinger ${ }^{13}$, S. Gupta ${ }^{18}$, K. E. Herkenhoff ${ }^{2}$, J. A. Hurowitz ${ }^{1}$, P. L. King ${ }^{19}$, S. Le Mouélic $^{20}$, L. A. Leshin ${ }^{21}$, R. Léveillé2 ${ }^{22}$ K. W. Lewis ${ }^{23}$, N. Mangold ${ }^{20}$, S. Maurice ${ }^{24}$, D. W. Ming $^{25}$, R. V. Morris ${ }^{25}$, M. Nachon ${ }^{20}$, H. E. Newsom ${ }^{16}$, A. M. Ollila ${ }^{16}$, G. M. Perrett ${ }^{6}$, M. S. Rice $^{13}$, M. E. Schmidt ${ }^{26}$, S. P. Schwenzer ${ }^{27}$, K. Stack ${ }^{13}$, E. M. Stolper ${ }^{13}$, D. Y. Sumner ${ }^{28}$, A. H.

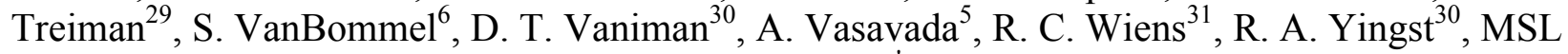
Science Team ${ }^{\dagger}$

\section{Affiliations:}

${ }^{1}$ Department of Geosciences, State University of New York at Stony Brook, Stony Brook, NY, 11794-2100, USA.

${ }^{2}$ U.S. Geological Survey, Astrogeology Science Center, Flagstaff, AZ 86001, USA.

${ }^{3}$ School of Earth and Space Exploration, Arizona State University, Tempe, AZ 85287, USA

${ }^{4}$ Space Research Centre, Dept. of Physics \& Astronomy, University of Leicester LE1 7RH, UK

${ }^{5}$ Jet Propulsion Laboratory, California Institute of Technology, Pasadena, CA 91109, USA.

${ }^{6}$ Department of Physics, University of Guelph, Guelph, ON, N1G 2W1, Canada

${ }^{7}$ Space Science Institute, Boulder, CO, USA

${ }^{8}$ Chemistry Division, Los Alamos National Laboratory, Los Alamos, NM, 87545, USA

${ }^{9}$ NASA Goddard Space Flight Center, Greenbelt, MD 20771, USA.

${ }^{10}$ Department of Space Sciences, NASA Ames Research Center, Moffett Field, CA 91109, USA.

${ }^{11}$ Laboratoire de Geologié de Lyon, Université de Lyon, 69364 Lyon, France.

${ }^{12}$ Department of Astronomy, Mt Holyoke College, South Hadley, MA 01075, USA.

${ }^{13}$ Division of Geological and Planetary Sciences, California Institute of Technology, Pasadena, CA 91125, USA

${ }^{14}$ UMR 7359 CNRS-Georesources, Campus des Aiguillettes, Faculté des Sciences, BP 70239 , 54506 Vandoeuvre Les Nancy, Cedex, France.

${ }^{15}$ IRAP, Université de Toulouse (UPS-OMP)/CNRS, 9, avenue du Colonel Roche, BP 44346, 31028 Toulouse, Cedex 4, France.

${ }^{16}$ Institute of Meteoritics, University of New Mexico, Albuquerque, NM 87131, USA.

${ }^{17}$ Center for Earth and Planetary Sciences, National Air and Space Museum, Smithsonian Institution, $6^{\text {th }}$ at Independence SW, Washington, DC 20560, USA. 
${ }^{18}$ Department of Earth Science and Engineering, Imperial College London, London, SW7 2AZ, UK.

${ }^{19}$ Research School of Earth Sciences, Australian National University, Canberra, ACT, 0200, Australia.

${ }^{20}$ Laboratoire de Planétologie et Géodynamique, LPGN/CNRS UMR 6112 and Université de Nantes, 4432 Nantes, France

${ }^{21}$ School of Science, Rensselaer Polytechnic Institute, Troy, NY 12180, USA.

${ }^{22}$ Canadian Space Agency, St-Hubert, QC, J3Y 8Y9, Canada.

${ }^{23}$ Princeton University, Princeton, NJ 08544, USA.

${ }^{24}$ Observatoire Midi-Pyrenees, Toulouse, France.

${ }^{25}$ NASA Johnson Space Center, Houston, TX 77058, USA.

${ }^{26}$ Department of Earth Sciences, Brock University, St. Catherines, ON L2S 3A1, Canada.

${ }^{27}$ CEPSAR, Open University, Milton Keynes MK7 6AA, U.K.

${ }^{28}$ Department of Earth and Planetary Sciences, University of California, Davis, CA 95616, USA.

${ }^{29}$ Lunar Planetary Science Institute, Houston, TX 77058, USA

${ }^{30}$ Planetary Science Institute, Tucson, AZ, 85719, USA

${ }^{31}$ International Space and Response Division, Los Alamos National Laboratory, Los Alamos, NM, 87545, USA.

*Correspondence to: Scott.McLennan@stonybrook.edu

${ }^{\dagger}$ MSL Science Team authors and affiliations are listed in the supplementary materials.

Abstract: Sedimentary rocks examined by the Curiosity rover at Yellowknife Bay, Mars, were derived from sources that evolved from approximately average Martian crustal composition to one influenced by alkaline basalts. No evidence of chemical weathering is preserved indicating arid, possibly cold, paleoclimates and rapid erosion/deposition. Absence of predicted geochemical variations indicates that magnetite and phyllosilicates formed by diagenesis under low temperature, circum-neutral $\mathrm{pH}$, rock-dominated aqueous conditions. High spatial resolution analyses of diagenetic features, including concretions, raised ridges and fractures, indicate they are composed of iron- and halogen-rich components, magnesium-iron-chlorine-rich components and hydrated calcium-sulfates, respectively. Composition of a cross-cutting dike-like feature is consistent with sedimentary intrusion. Geochemistry of these sedimentary rocks provides further evidence for diverse depositional and diagenetic sedimentary environments during the early history of Mars.

Introduction: Shortly after leaving its landing site at Bradbury Landing in Gale crater, the Mars Science Laboratory Curiosity rover traversed to Yellowknife Bay (1), where it encountered a flat-lying, $\sim 5.2$ meter thick succession of weakly indurated clastic sedimentary rocks ranging from mudstones at the base to mainly sandstones at the top (2). Stratigraphic relationships and 
sedimentary structures indicate that this coarsening-upward succession likely represents sedimentation in an ancient fluvio-lacustrine system that would have been habitable. Also preserved is a spectrum of diagenetic features, including concretions, void spaces with a variety of sizes, geometries and origins, early diagenetic fractures ("raised ridges") filled with banded (possibly silicate) cements, possible sedimentary dikes, and a later diagenetic fracture system filled with sulfate cements, all indicating extended post-depositional aqueous fluid flow through the rocks (2).

Curiosity fully applied its analytical payload to investigate these sedimentary rocks and determine lithological, textural, chemical, mineralogical and isotopic compositions and their stratigraphic relationships (2-4). The payload of Curiosity includes two instruments capable of measuring elemental abundances. The alpha particle X-ray spectrometer (APXS) determines abundances on $\sim 2.25 \mathrm{~cm}^{2}$ surfaces and, when used in conjunction with the dust removal tool (DRT) or drilling system, can analyze relatively clean surfaces and drill cuttings. The laserinduced breakdown spectrometer (LIBS), part of the ChemCam remote sensing suite, detects atomic emission spectra from areas of $\sim 0.1-0.3 \mathrm{~mm}^{2}$ (depending on standoff distance), $>2$ orders of magnitude smaller than APXS. LIBS offers the additional capability of laser depth profiling (including surface dust removal) of up to $\sim 1000 \mu \mathrm{m}$. These instruments provide complementary data by revealing both bulk rock compositions and compositions that can be related directly to textural features.

On Earth, the elemental geochemistry of clastic sedimentary rocks provides information central to interpreting sedimentary history, including chemical weathering history, nature and composition of the sediment provenance, sediment transport, and diagenetic history (5-10). In turn, geochemical understanding of these issues constrains many fundamental geological questions such as paleoclimates, tectonic relationships, basin evolution, diagenetic fluid flow and even crust-mantle evolution (7,11-15). Experience from the Mars Exploration Rovers Spirit and Opportunity, orbital spectroscopy and experiments using Mars-like compositions shows that such approaches are applicable to sedimentary environments on Mars where primary igneous compositions and aqueous conditions may differ from our terrestrial experience (12,16-24). Accordingly, we report elemental geochemistry of the ancient sedimentary rock succession, including its diagenetic features, preserved within Yellowknife Bay, evaluate these compositions in terms of the sedimentary history of this habitable paleoenvironment within Gale crater and place them within the context of Martian surface environments early in the planet's history.

Yellowknife Bay Stratigraphy: The geology, stratigraphy, sedimentology and diagenetic history of Yellowknife Bay are described elsewhere (2). The sedimentary sequence, informally named the Yellowknife Bay formation, is subdivided into three members (Fig. 1) that likely were deposited in a prograding alluvial fan fluvio - lacustrine depositional system and influenced by at least two distinct diagenetic events. The formation is likely Hesperian in age but poorly constrained and could lie anywhere between early Hesperian ( 3.7-3.4 Ga), if part of the early Gale crater fill, to late Hesperian or early Amazonian $(\sim 3.4-1.5 \mathrm{Ga})$, if coeval with the nearby Peace Vallis alluvial fan exposed in Gale crater (2).

The stratigraphically lowest Sheepbed member ( $>1.5$ meter thick), whose base is not exposed, is composed of gray-colored, bedded mudstone. Fine-grained texture, laterally extensive decimeter-scale bedding and stratigraphic relationships indicate deposition from suspension, likely in a distal alluvial fan lacustrine (or less likely playa) environment but possibly as ash fall. Early diagenetic textures, forming prior to or during lithification, include 
millimeter-scale nodules interpreted as concretions, millimeter-scale rimmed "hollow nodules" interpreted as void space possibly formed by gas expulsion during early diagenesis, and narrow centimeter-sized intersecting "raised ridges", laterally correlative to nodules and hollow nodules, possessing resistant isopachous cements lining ridge margins, and interpreted as diagenetic cracks formed in early lithified sediment probably by reactions involving pore fluids (see Figs. $6 \mathrm{~A}-\mathrm{C}, 7$ in ref. 2). The upper $\sim 50-75$ centimeters of the Sheepbed member weathers more recessively than underlying beds and possesses higher abundances of both early and late diagenetic features. For geochemistry, we further subdivided the Sheepbed member into lower and upper parts with the boundary $\sim 30$ centimeters beneath the Gillespie Lake member in order to evaluate compositional transitions into the overlying stratigraphic unit.

The 2.0 meter thick Gillespie Lake member overlies the Sheepbed member with a sharp, likely erosional, contact. It consists of thin to medium bedded medium- to very coarse-grained sandstones with relict centimeter-scale cross-bedding. Mars Hand Lens Imager (MAHLI) and ChemCam Remote Micro-Imager (RMI) images indicate textural immaturity and compositionally diverse grains (see Fig. 5D in ref. 2). This member was likely deposited in a distal fluvial environment. Gillespie Lake sandstones exhibit little primary porosity, suggesting a cemented rock, but may contain secondary porosity in the form of dispersed millimeter-scale vugs that may result from leaching of detrital grains or early diagenetic phases during fluid circulation or perhaps selective loss of readily degraded mudstone intraclasts during weathering (2). The Sheepbed (including early diagenetic features) and Gillespie Lake members are both cross-cut by a network of later diagenetic (post-lithification) intersecting fractures of variable thickness (hairline to $\sim 8$ millimeters) filled with light-toned cement, identified as Ca-sulfate by a variety of measurements (see below). These filled fractures are most abundant within the uppermost Sheepbed and the bright cements also fill hollow nodules where they intersect with fractures. Also cross-cutting the upper Sheepbed member is a $\sim 8$ centimeter wide dike-like feature termed the "snake", that terminates in a small anticline within the middle Gillespie Lake member, and is interpreted as a sedimentary dike injected due to high pore pressures that developed during rapid burial (2). A detailed 1.5 meter stratigraphic section, termed the Selwyn Section, was measured across the Sheepbed - Gillespie Lake contact (Fig. 1, Fig. S1).

The upper Glenelg member ( 1.7 meters thick) is lithologically heterogeneous (2). The lower $\sim 40$ centimeters (e.g., Point Lake outcrop) is poorly understood but notable in possessing abundant millimeter- to centimeter-scaled voids. Possible interpretations include a debris flow, volcaniclastic layer, gas-charged sedimentary sill, perhaps related to the "snake", or a vesiclerich volcanic flow (although there is no evidence for a nearby contemporaneous volcanic source). Some voids and cross-cutting fractures are filled with light-toned minerals, identified as Ca-sulfate by ChemCam, reminiscent of fracture fillings in the Sheepbed and Gillespie Lake members. We assume this part of the Glenelg is also sedimentary but are mindful of this uncertainty. The upper part of the Glenelg member (e.g., Shaler outcrop) consists of commonly cross-bedded interstratified sandstones and recessive finer grained sediment and was likely deposited mainly by fluvial processes, with paleocurrents indicating a source derived from the direction of the crater rim. At the top of this member are discontinuous fine-grained beds (e.g., Bathurst Inlet), in some cases with distinctive chemical compositions and possibly with distinctive origins (see below).

Mineralogical and Geochemical Constraints from CheMin and SAM: Two locations within the upper Sheepbed member, corresponding to APXS targets John_Klein and 
Cumberland, were drilled with recovered powders being sieved $(<150 \mu \mathrm{m})$ and delivered to CheMin and SAM for X-ray diffraction analysis of mineralogy and chemical - isotopic measurements of evolved gases using gas chromatography, quadrupole mass spectrometry and tunable laser spectrometry $(3,4)$. Unsurprisingly for clastic sediments, both samples are composed of non-equilibrium mineral assemblages including primary igneous and a variety of secondary phases, notable for a $\sim 30-40 \%$ amorphous component (including allophane-like material) and $\sim 20 \%$ trioctahedral phyllosilicates. The remaining crystalline mineralogy includes (in decreasing amount) plagioclase, pyroxene, magnetite, Ca-sulfate (anhydrite, bassanite), forsteritic olivine (John_Klein only), akaganeite, sanidine, pyrrhotite and possibly $(<1-2 \%)$ hematite, ilmenite, pyrite, quartz and halite. The exact mineralogy of the trioctahedral phyllosilicates is not fully constrained but they consist of a $\sim 10 \AA$ collapsed saponitic smectite in John_Klein and, in Cumberland, clay minerals with both $\sim 10 \AA$ and $\sim 13.2 \AA$ spacing, possibly reflecting poorly-formed vermiculite (lacking the $7 \AA$ peak) or a smectite with either an interlayer cation with high hydration energy (e.g., $\mathrm{Mg}$ ) or metal-hydroxy-groups (i.e., incipient chlorite). SAM analyses are also consistent with smectite, sulfates, sulfides, Fe-oxides and further indicate oxychlorine compounds (e.g., chlorate and/or perchlorate). Both instruments indicate heterogeneous Fe- and S-redox states. Mass balance calculations provide estimates of the chemical compositions of the combined amorphous component plus phyllosilicates and remaining crystalline minerals and these compositions (4) are used below.

Clastic Sedimentary Rocks: Yellowknife Bay S- and Cl-free compositions (all on weight percent basis) determined by APXS (25) (Tables S1-S4) correspond to iron-rich basalt (i.e., $\mathrm{SiO}_{2}$ mostly $<48 \%$; $\mathrm{FeO}_{\mathrm{T}}$ mostly $>20 \% ; \mathrm{MgO} \approx 8-10 \%$; Ni $\approx 200-900$ ppm). Alkalis are variable $\left(\mathrm{Na}_{2} \mathrm{O}+\mathrm{K}_{2} \mathrm{O} \approx 3-6 \% ; \mathrm{K}_{2} \mathrm{O} / \mathrm{Na}_{2} \mathrm{O} \approx 0.2-1.3\right)$. CaO is highly variable $(\approx 5-25 \%)$ but values above $\sim 7 \%$ correspond to high $\mathrm{SO}_{3}$, indicative of elevated levels of Ca-sulfate. Typical for the Martian surface, both $\mathrm{SO}_{3}$ and $\mathrm{Cl}$ are mostly elevated in APXS observations due in part to surface soil and dust contamination. On brushed surfaces, APXS measurements of $\mathrm{SO}_{3}$ are as low as $0.9 \%$ (Werneke_Brush, the analysis on the brushed surface of the Werneke target) suggesting the sedimentary rocks may have no more than $1-2 \% \mathrm{SO}_{3}$ on average. On the other hand, $\mathrm{Cl}$ abundances are higher than in most Martian soils (26), reaching 1.9\% and commonly leading to low $\mathrm{S} / \mathrm{Cl}$ ratios. Elevated $\mathrm{Cl}$ abundances $(\geq 1 \%)$ are likely a primary rock feature rather than resulting from soil/dust coatings, consistent with the presence of oxychlorine compounds, akaganeite and possibly halite $(3,4)$. Up to $9 \%$ magnetite in the crystalline component of Sheepbed mudstone drill samples was detected by XRD (4). We cannot completely exclude the possibility that very fine-grained magnetite was delivered as part of the detrital load into a lake environment, but on balance geochemistry suggests magnetite is not detrital. For example there are no systematic relationships between $\mathrm{FeO}_{\mathrm{T}} / \mathrm{MgO}$ and $\mathrm{FeO}_{\mathrm{T}}$ that could be explained by magnetite variations, no evidence from XRD (4) for enrichments of other minerals that might be expected to form part of a heavy mineral suite (e.g., spinels) nor correlations with related structural elements of these minerals (e.g., $\mathrm{Cr}$, Ti) and no geochemical evidence, from APXS or ChemCam, for detrital magnetite enrichments (e.g., Fe-enrichment) in immediately overlying Gillespie Lake sandstones where heavy minerals might be expected to concentrate even more. Absence of geochemical evidence for detrital magnetite is also consistent with deposition of the Sheepbed mudstones from suspension into a lake, where heavy mineral concentrations are unlikely $(2,4)$. Thus, magnetite is most likely a diagenetic phase rather than a detrital component. 
Geochemical relationships are well illustrated in ternary diagrams plotting mole fractions $\mathrm{Al}_{2} \mathrm{O}_{3}-\left(\mathrm{CaO}+\mathrm{Na}_{2} \mathrm{O}\right)-\mathrm{K}_{2} \mathrm{O}$ (or $\left.\mathrm{A}-\mathrm{CN}-\mathrm{K}\right)$ and $\mathrm{Al}_{2} \mathrm{O}_{3}-\left(\mathrm{CaO}+\mathrm{Na}_{2} \mathrm{O}+\mathrm{K}_{2} \mathrm{O}\right)-\left(\mathrm{FeO}_{\mathrm{T}}+\mathrm{MgO}\right)$ (or A-CNK-FM) (Fig. 2). On these diagrams igneous minerals plot on or below the plagioclase - Kfeldspar (A-CN-K) and feldspar - FM (A-CNK-FM) joins whereas secondary clay minerals plot above (27). The Chemical Index of Alteration (CIA), defined as $100 * A /(A+C+N+K)$, reveals any chemical weathering history by quantifying the systematic loss of relatively mobile elements (i.e., $\mathrm{Ca}, \mathrm{Na}, \mathrm{K}$ ) from silicate minerals, and the scale is plotted beside the A-CN-K diagrams. For mafic sources, CIA above $40-45$ in bulk sediment suggests some chemical weathering history and above $\sim 50-55$ provides fairly compelling evidence for open system weathering (10). ChemCam (Fig. 2C, D) analyzed many more targets than APXS (Fig. 2A, B), and given the strategy of using its greater spatial resolution to target textural features (e.g., veins, ridges, grains), more scatter is both expected and observed. Mission experience so far indicates a slight instrument bias with ChemCam data plotting at higher $\mathrm{Al}_{2} \mathrm{O}_{3}$ on these diagrams than APXS, especially for alkali-rich compositions. Nevertheless, the analyses provide consistent geochemical trends.

Lower Sheepbed and Gillespie Lake bulk rock compositions (Fig. 2A,B) are very tightly grouped, and slightly more mafic than average Martian crust (closer to FM apex). Most upper Sheepbed samples plot in a similar position but several trend towards the CN and CNK apexes, where Ca-sulfate plots. ChemCam analyses (Fig. 2C, D) show a more complete linear trend, with one end member defined by Ca-sulfates within the light-toned fractures and filled hollow nodules that were targeted for analysis. The Glenelg member has bulk compositions that commonly differ from both average crust and Sheepbed/Gillespie Lake, with less relative amounts of $\mathrm{FeO}_{\mathrm{T}}+\mathrm{MgO}$ and higher $\mathrm{K}_{2} \mathrm{O}$ in some samples, characteristics confirmed by ChemCam analyses that also show evidence for detrital feldspar (Fig. 2D). An analysis of APXS data for the Yellowknife Bay formation samples Bathurst Inlet and Rocknest3, as well as the float rocks Jake_Matijevic (Jake_M) and Et Then on Bradbury Rise, which have been inferred to be volcaniclastic or igneous, shows that the elemental relationships among these rocks are consistent with physical mixing between Bathurst Inlet-like and Jake_M-like material with addition of an Fe-rich cement or rind, especially apparent in Et_Then (28). Some ChemCam analyses plot above the plagioclase - K-feldspar and feldspar - FM joins suggesting phyllosilicate-rich targets, consistent with the identification of phyllosilicates by XRD (4). In addition, some ChemCam Sheepbed analyses plot closer to the FM apex, consistent with the identification of $\mathrm{Mg}-\mathrm{Fe}-\mathrm{Cl}$-rich phases associated with raised ridges (also observed in the McGrath APXS raster) that were also targeted for analysis (see below) and the $\mathrm{Fe}^{3+}$-rich phases identified by XRD (e.g., magnetite, akaganeite, and possibly hematite).

Despite identifying phyllosilicates in Sheepbed mudstones by XRD (4) and inferring them from ChemCam (Fig. 2C,D), the geochemistry of the Yellowknife Bay formation provides scant support for any substantial chemical weathering history affecting the sources or the sediment during transport into the depositional basin. During circum-neutral $\mathrm{pH}$ weathering, clay minerals form at the expense of primary igneous phases, with loss of mobile elements. As a result, bulk sedimentary rock compositions that have been influenced by weathering, including those derived from mafic sources, typically plot above the plagioclase - K-feldspar and feldspar - FM joins (29-31). Similarly, any clay minerals that formed by hydrothermal alteration (e.g., impact-related) in surrounding regions and transported into the Yellowknife basin would also carry comparable distinct chemical signatures $(22,32-34)$. Nor is any evidence observed for low $\mathrm{pH}$ alteration conditions, in the form of $\mathrm{Fe}^{3+}$ mobility and associated formation of $\mathrm{Fe}^{3+}$-sulfates, 
such as that observed by the Spirit and Opportunity rovers (35-37). During transport, clays concentrate in fine-grained sediment (i.e., Sheepbed) compared to associated coarse-grained sediment (i.e., Gillespie Lake) but no evidence for the predicted geochemical fractionation related to hydraulic segregation of sediment types (including clay minerals and magnetite) is observed in the bulk analyses of either unit.

One complicating factor is that secondary Ca-sulfate might lower apparent CIA values and mask evidence for chemical weathering (27). However, on a plot of CIA versus $\mathrm{SO}_{3}$ content (Fig. 3), this clearly is not the case. At high $\mathrm{SO}_{3}$, indicative of sulfates, CIA falls to lower values as expected but at lower $\mathrm{SO}_{3}$, CIA levels off to values typical of Martian mafic igneous rocks thus indicating that none of these samples has witnessed a substantial chemical weathering history. This is also consistent with sample positions on the A-CNK-FM diagram (Fig. 2B). Accordingly, formation of phyllosilicates within Sheepbed mudstones likely resulted from diagenetic processes that did not noticeably influence bulk rock composition, implying rockdominated (i.e., low water/rock ratio) post-depositional aqueous fluid conditions.

Both major and trace elements exhibit stratigraphic trends (Fig. 4). To avoid variations in absolute abundances imparted by simple dilution effects of Ca-sulfate, we plot ratios among elements most often associated with siliciclastic components. On a plot of $\mathrm{K}_{2} \mathrm{O} / \mathrm{Al}_{2} \mathrm{O}_{3}$ versus $\mathrm{TiO}_{2} / \mathrm{Al}_{2} \mathrm{O}_{3}$ (Fig. 4A) the Glenelg member includes samples with higher $\mathrm{K}_{2} \mathrm{O} / \mathrm{Al}_{2} \mathrm{O}_{3}$ and generally have slightly more variable $\mathrm{TiO}_{2} / \mathrm{Al}_{2} \mathrm{O}_{3}$, compared to the Sheepbed and Gillespie Lake members. The two analyses from the rock Bathurst Inlet, from the top of the Glenelg member, are especially distinctive in having the highest $\mathrm{K}_{2} \mathrm{O} / \mathrm{Al}_{2} \mathrm{O}_{3}$ ratios. These differences are interpreted to represent a notable change in the provenance from which sediment particles were derived to include more alkali-rich basalts higher in the stratigraphic section.

Subtle differences in bulk composition also exist within the Sheepbed member itself, with the upper part of the member having slightly lower and more variable $\mathrm{TiO}_{2} / \mathrm{Al}_{2} \mathrm{O}_{3}(x=0.104$, $s . d .=0.011)$ than the lower part $(x=0.116, s . d .=0.006)$. This could also be a subtle provenance effect $(38,39)$, although relationships between $\mathrm{TiO}_{2} / \mathrm{Al}_{2} \mathrm{O}_{3}$ ratio and overall bulk composition is complex in detail, especially because all compositions are basaltic $(12,40)$. In addition, small variations in plagioclase content that are ultimately related to sedimentary sorting effects (24), could also play a role in changing the $\mathrm{TiO}_{2} / \mathrm{Al}_{2} \mathrm{O}_{3}$ ratio (Fig. 4A).

Stratigraphic variations in APXS trace elements are summarized on a plot of $\mathrm{Cr} / \mathrm{Ni}$ versus $\mathrm{Zn} / \mathrm{Ni}$ (Fig. 4B). In this case, the Glenelg member has higher and/or more variable ratios than the Sheepbed member, related to combinations of elevated $\mathrm{Zn}$ and $\mathrm{Cr}$ and lower Ni. There is also a difference between the Gillespie Lake sandstone and Sheepbed mudstones, related mainly to lower Ni in the former, although only a single high quality analysis is available for the Gillespie Lake member. Major elements indicate a similar provenance and so the reason for this is not clear. A heavy mineral effect is one possibility but would be more likely to cause an enrichment of $\mathrm{Cr}$ (chromite) rather than depletion of $\mathrm{Ni}$ in the sandstones. Thus, in Glenelg sandstones, Ni is similarly low ( 200-400 ppm) as in the Gillespie Lake sandstone sample but Cr reaches very high levels ( $>5,000 \mathrm{ppm})$ consistent with a heavy mineral (chromite) enrichment predicted by fluvial processing (41). Within the Sheepbed member, the upper part has lower $\mathrm{Cr} / \mathrm{Ni}$ and $\mathrm{Zn} / \mathrm{Ni}$, related mainly to higher $\mathrm{Ni}$, consistent with a slightly different, but still mafic, provenance.

Lithium contents measured by ChemCam (42) also reveal a stratigraphic trend (Fig. 4C) with Sheepbed mudstones having low and uniform abundances $(x=4.3 \mathrm{ppm} ; s . d .=2.4 \mathrm{ppm})$ 
whereas the overlying units have about a factor of two higher and much more variable Li abundances. Although secondary aqueous processes, such as hydrothermal activity, can enrich Li (43) and evidence for centimeter-scale Li redistribution is observed in diagenetic raised ridges (see below), this range for average values probably cannot be distinguished from variations in basaltic provenance given our limited understanding of Li distributions in the Martian crustmantle system.

Early Diagenetic Features: Efforts were made to characterize chemical and mineralogical controls on concretion formation within the Sheepbed member. Numerous ChemCam observations were directed at concretions but no systematic differences were observed, limiting compositional differences between concretion and host sediment to less than $\sim 10 \%$ for major elements. APXS analyses of drill fines from concretion+hollow nodule-rich (Cumberland) and concretion+hollow nodule-poor (John_Klein) areas were also examined (25, Table S5). Samples delivered to the internal instruments (CheMin and SAM) that determined mineralogy $(3,4)$ are preferable and can be analyzed by APXS after being dumped onto the surface when CheMin and SAM analyses are complete (as for John_Klein). However, at the time of writing, Curiosity was still carrying the Cumberland sample and consequently it has not been analyzed by APXS and instead analysis of the fines that accumulated around the drill hole from the drilling process were used. Additionally, imaging of drill hole walls indicates John_Klein has greater amounts of Ca-sulfate-filled fractures (see below). A two-stage calculation was thus performed to evaluate results. First, 5\% anhydrite was removed from the John_Klein composition to put $\mathrm{SO}_{3}$ at similar concentrations in both samples, and broadly consistent with mapping veins in drill hole walls (4). Second, two gain-loss calculations were performed assuming $\mathrm{Ti}$ and $\mathrm{Al}$, respectively, are constant between samples. Elements enriched (taken as $\geq 5 \%$ in both calculations) in Cumberland include $\mathrm{Fe}, \mathrm{Ca}, \mathrm{Cl}, \mathrm{Br}, \mathrm{Ni}$ and $\mathrm{Ge}$. Elevated $\mathrm{Ca}$ is difficult to interpret given the Ca-sulfate in fractures but elevated $\mathrm{Fe}, \mathrm{Cl}, \mathrm{Br}$ and $\mathrm{Ni}$ are consistent with small amounts of a minor mineral such as akaganeite, identified by XRD, forming at least part of the concretion cement (4).

ChemCam and APXS analyses of isopachous cements within early diagenetic raised ridges indicate the presence of a $\mathrm{Mg}-\mathrm{Fe}-\mathrm{Cl}$ rich phase (or assemblage). ChemCam confirms that the amount of $\mathrm{MgO}$ is as high as $\sim 17 \%$, and in places is accompanied by elevated Li (Fig. 5A). The observation that $\mathrm{Li}$ and $\mathrm{Mg}$ are not well correlated across the different layers of isopachous cements (e.g., right hand side of Fig. 5A image) suggests a complex origin. APXS rasters on the raised ridge target $\mathrm{McGrath}$ further indicates elevated $\mathrm{Fe}$ and that both $\mathrm{Mg}$ and Fe correlate with $\mathrm{Cl}$, although enrichment of any chloride phase or oxychlorine compound explains only a tiny part of the Mg-Fe variation (Fig 5B). A mass balance calculation using the highest and lowest APXS MgO analyses from the McGrath raster (McGrath-R1 and -R2) and assuming the component is $\sim 20 \%$ of the rock indicates a composition of $\mathrm{SiO}_{2} \sim 45 \%$; $\mathrm{FeO}_{\mathrm{T}} \sim 35 \%$; $\mathrm{MgO} \sim 18 \%$, $\mathrm{Cl} 3 \%$ and $\sim 1,300-1,500 \mathrm{ppm}$ each for $\mathrm{Ni}, \mathrm{Zn}$ and $\mathrm{Br}$ (25, Table S6). Such a composition cannot be accommodated by any single phase identified in the drilled samples by XRD, but perhaps is consistent with a mixture of Mg-rich, Al-deficient smectitic clay (e.g., hectorite, stevensite) and halogen-bearing Fe-oxides (e.g., akaganeite).

Late Diagenetic Features: Both ChemCam and APXS provide constraints on the mineralogy of cross-cutting late diagenetic light-toned fractures, including filled hollow nodules. ChemCam shots on these features (Fig. 5C) show elevated Ca, S and in places $\mathrm{H}$, indicating multiple hydration states of Ca-sulfate. ChemCam also measured elevated Sr content (up to 450 
ppm) in the fracture fills (Fig. 5C), as expected for Ca-sulfate (44). The presence of multiple Casulfate minerals is also consistent with CheMin XRD analyses that identified anhydrite and bassanite (but not gypsum) and MastCam VNIR spectroscopy that suggests that some fracture fills are hydrated, possibly indicating gypsum (4). Finally, APXS raster analysis on the fracture fill target Sayunei also indicates the presence of Ca-sulfates through a correlation between $\mathrm{CaO}$ and $\mathrm{SO}_{3}$, the slope of which is consistent with $\mathrm{CaSO}_{4}$ stoichiometry (Fig. 5D).

The composition of the dike-like "snake" feature (Snake_River target) may bear on its origin The Snake_River major element composition is most similar to sedimentary rocks in the lower part of the Y ellowknife Bay formation and best matches the lower Sheepbed member for major elements (Fig. 6A); it differs from the Gillespie Lake member for S, Cl and all trace elements (Fig. 6B). Although close similarity exists with individual analyses of the heterogeneous Glenelg member, the "snake" does not compare favorably to the Glenelg average for a number of elements (Fig. 6C) suggesting it probably did not result from infall of overlying sediment into a fracture. These comparisons indicate that the composition of the snake is consistent with a sedimentary dike, as suggested from stratigraphic relationships (2), intruded from the Sheepbed or unexposed sediments at lower stratigraphic levels and not currently exposed. In detail, its trace element composition differs from all exposed units (higher $\mathrm{Cr}$, lower Ni) suggesting an origin from a different, presumably lower, stratigraphic level.

Discussion: Elemental geochemistry reveals a fundamental provenance change during deposition of the Yellowknife Bay formation. Clastic sediments of the Sheepbed and Gillespie Lake members were derived from a source similar to the average Martian crust but slightly more mafic and Fe-rich $\left(\mathrm{SiO}_{2} \sim 46 \%\right.$ vs $49 \%$; $\mathrm{FeO}_{\mathrm{T}} \sim 21.5 \%$ vs $\left.18 \%\right)$, whereas high-K alkaline igneous rocks contribute substantially to the Glenelg member provenance. The change in provenance may be related to erosional evolution of drainage basins feeding the alluvial fan system. Downcutting fluvial channels in the catchment of the fan system may have encountered a distinct alkaline basalt bedrock lithology (likely related to Jake_Matijevic-type composition) or captured a drainage underlain by such lithologies leading to the abrupt change in sediment provenance. On the other hand, alkaline basalts of the type suggested to be incorporated into Glenelg sediments are rare on Earth (45) and having them represent a dominant provenance component in distal facies of a fluvial system is unexpected and could suggest that such rocks, which have also been observed in Gusev Crater (46), are more common on Mars than previously thought (45-47). An alternative possibility is that an exotic source of alkaline basalts was locally introduced into the basin, by way of volcanic ash or flows, and reflecting relatively small volumes of alkaline basalt that in turn were locally recycled and preserved as volcaniclastic layers. This scenario is consistent with the observation that high-K signatures appear restricted to certain beds within the Glenelg member. Given the limited stratigraphic distribution that has been studied (Glenelg member exhibiting the high-K signature represents only $\sim 1.7$ meters of a $\sim 5$ meter section) it is not possible to distinguish whether relatively local or more regionally exposed high-K lithologies caused the provenance change and thus the scale of any potential alkaline igneous province is not well constrained from the sedimentary data.

Martian soils likely contain a small ( 1-3\%) meteoritic component (48) and estimates of crustal composition (notably Ni) are derived by assuming a $2 \%$ meteoritic soil component (12). Sheepbed mudstones, if deposited in an ancient lake that represented the terminus of a watershed, might be expected to contain meteoritic material that was swept into the basin. Provenance effects alone can explain the levels of Ni ( 450-850 ppm) in the Sheepbed member 
given the slightly more mafic and Fe-rich composition, compared to average Martian crust. However, trace element data are also consistent with a modest meteoritic contribution. Modeling the effects of adding an average CI-type carbonaceous chondrite composition to average Martian crust and to one of the brushed lower Sheepbed analyses (Ekwir_Brush) shows that the low $\mathrm{Cr} / \mathrm{Ni}$ and $\mathrm{Zn} / \mathrm{Ni}$ ratios of the Sheepbed member are consistent with $\sim 1-4 \% \mathrm{CI}$ component, with a larger amount in the upper part of the member (Fig. 4B). For typical CI-type chondritic compositions (49), a 1-4\% meteoritic component could also deliver as much as $\sim 300-1,200 \mathrm{ppm}$ organic C, consistent with low levels of carbon detected by SAM (3).

In the absence of a fossil record, sediment chemistry is one of the few tools available to evaluate paleoclimate, by constraining chemical weathering intensity $(10,50,51)$. Low CIA values and positions on A-CN-K and A-CNK-FM diagrams for the Yellowknife Bay formation (Fig. 2) indicate very limited chemical weathering prior to deposition. The similarity between major elements of the Gillespie Lake bedload-dominated sandstones and Sheepbed member suspended load-dominated mudstones also suggests that the fluvial system carried a very high ratio of solid to dissolved river loads $\left(\mathrm{L}_{s} / \mathrm{L}_{d}\right)$, which in turn results from both arid conditions and rapid erosion and transport $(51,52)$ and could have been further enhanced by cold conditions that would kinetically inhibit chemical weathering reactions. Accordingly, Yellowknife Bay formation geochemistry is consistent with some combination of a highly arid, possibly frigid, climate and/or a high relief fluvial system, and probably both. On early Mars, impact processes may have aided in the generation of sedimentary particles, increasing the efficiency of physical denudation $(53,54)$. Surface waters with low $\mathrm{L}_{d}$ significantly contrasts with the high ionic strength ancient surface waters suggested at Meridiani Planum (55), even though both apparently record evidence of an arid climate system. In spite of the suggested arid conditions, relatively small amounts of chemical sedimentation (e.g., sulfates, carbonates, chlorides) may be expected in the Yellowknife Bay sedimentary system. In addition, to the degree that this surface water contributes to the regional groundwater system, it would also tend to promote dilute, circumneutral subsurface aqueous conditions.

Elemental geochemistry also provides constraints on diagenetic history. The uniform bulk rock compositions of Sheepbed mudstones is particularly important, along with its suite of complex diagenetic features, which suggest post-depositional aqueous alteration took place at combined low water/rock ratios and $\mathrm{pH}$ levels modest enough that mineralogical changes took place under nearly isochemical conditions; very little mass has been removed from the system. Therefore, the broad array of secondary minerals identified by XRD, including saponitic phyllosilicates, magnetite, akaganeite, hematite and perhaps a substantial part of the amorphous component, needs to be explained by plausible reactions taking place within the sediment (4). One important exception is that textural and geochemical relationships indicate Ca-sulfates, found in fractures, voids and hollow nodules, were later "added" to the rock and not formed by local redistribution of elements during the earlier stage of diagenesis that transformed the Sheepbed sediment to rock. Thus, at least two distinct diagenetic fluid events took place with distinct fluid chemistry. The first fluid event (perhaps more than one event, given the mineralogical complexity, including co-existence of magnetite, akaganeite, pyrrhotite and possibly hematite and pyrite) resulted in the mineral assemblage within the host sediment (and perhaps the $\mathrm{Fe}-\mathrm{Mg}-\mathrm{Cl}$-rich assemblage associated with early diagenetic raised ridges). Plausible reactions that could be involved include olivine $(+\mathrm{Al}) \Rightarrow$ saponite + magnetite $(4)$ and pyrrhotite $(+$ pyrite? $) \Rightarrow$ akaganeite ( $\Rightarrow$ hematite?), the latter of which would be promoted by $\mathrm{Cl}^{-}$-bearing 
fluids that also in turn could have promoted concretion formation. Sometime after lithification, an additional fluid event, presumably originating from deeper within the section and associated with fracturing of the mudstone, injected fluids that became saturated with respect to Ca-sulfate (typically early precipitated minerals in evolving brines) due to changing chemistry and/or pressure-temperature conditions. These fluids precipitated sulfates within the fractures, and filled any void spaces that the fractures intersected, including the hollow nodules. Although considerable modeling and experimental effort will be required to fully understand these processes, it is possible to construct simple forward thermochemical aqueous models broadly consistent with these observations (25, Fig. S8).

Our findings add to the growing evidence for highly diverse sedimentary environments on early Mars $(2,56,57)$. The Burns formation of Meridiani Planum is the only sedimentary sequence that has been studied in situ in comparable detail and is of similar age - if anything even older $(20,57,58)$. Although both represent clastic sedimentation derived from basalt sources and influenced by complex groundwater diagenesis, the sedimentary history is strikingly different. For example, where the Burns formation preserves evidence for very low $\mathrm{pH}$ and very high ionic strength groundwater, the Yellowknife Bay formation had relatively dilute circumneutral groundwater. Where the Burns formation is dominated by chemically precipitated constituents (sulfates, chlorides) derived from evaporation of acidic brines, Yellowknife Bay mudstones contain very little in the way of chemically precipitated constituents and, apart from cross-cutting Ca-sulfate veins, the secondary mineralogy formed mostly within a largely closed geochemical system. Where the basaltic debris within the Burns was substantially chemically weathered prior to deposition, Yellowknife Bay detritus appears to be essentially unweathered. Orbital spectroscopic mapping suggests that surface aqueous environmental conditions on early Mars (late Noachian) evolved from circum-neutral clay-rich to acidic sulfate-rich settings (59) but it would appear, just like on Earth where evolving global environments are also reflected in the broad sweep of the sedimentary record (60), that when faced with rocks on the ground, geological complexity is apparently inevitable.

Materials and Methods: APXS is a well-established analytical technique on Mars, providing quantitative abundance data for major and minor elements, including $\mathrm{S}$ and $\mathrm{Cl}$, and trace elements $\mathrm{Cr}, \mathrm{Ni}, \mathrm{Zn}, \mathrm{Ge}$ and $\mathrm{Br}(61)$. Analytical details are provided in the supplemental information (25) and Yellowknife Bay formation results are provided in Tables S1-S4. Multiple APXS analyses were sometimes obtained on the same rock but at different locations. In some cases (e.g., Bathurst Inlet) both analyses are considered because they represent slightly different stratigraphic levels. However, where multiple analyses were made at a single site, such as drill sites (e.g., John_Klein, Cumberland) and APXS "rasters" (e.g., Sayunei, McGrath), the analysis with lowest $\mathrm{SO}_{3}$ was selected as most representative of the sedimentary rock because brushed surfaces indicate low $\mathrm{SO}_{3}$ and mapping of borehole walls suggests Ca-sulfate abundances correlate with diagenetic light-toned veins and hollow nodule fills. APXS "rasters", involving multiple, closely spaced measurements, were employed on two diagenetic features: fracture fills (Sayunei) and raised ridges (McGrath) and these results are provided in Table S4, which also includes the suggested sedimentary dike (Snake River analysis). The ChemCam LIBS instrument provides semi-quantitative analyses for major and some minor and trace elements (e.g., $\mathrm{Ba}, \mathrm{Rb}, \mathrm{Sr}, \mathrm{Li}$ ) using multiple laser pulses (shots) on $\sim 350-550 \mu \mathrm{m}$ diameter targets from up to 7 meters distance $(62,63)$. The first $\sim 5$ shots remove surface dust and the rock analyses are based on averages of subsequent shots. Further analytical details are provided in the supplemental information (25). 


\section{References and Notes:}

1. Names have been assigned to certain areographic features by the Mars Science Laboratory (MSL) team for planning and operations purposes. The names are not formally recognized by the International Astronomical Union.

2. J. P. Grotzinger et al., A habitable fluvio-lacustrine environment at Yellowknife Bay, Gale crater, Mars. Science, submitted (2013).

3. D. W. Ming et al., Volatile and organic compositions of sedimentary rocks at Yellowknife Bay, Gale crater, Mars. Science, submitted (2013).

4. D. T. Vaniman et al., Mineralogy of a mudstone at Yellowknife Bay, Gale Crater, Mars. Science, submitted (2013).

5. H. W. Nesbitt, G. M. Young, Early Proterozoic climates and plate motions inferred from major element chemistry of lutites. Nature 299, 715-717 (1982).

6. H. W. Nesbitt, G. M. Young, Petrogenesis of sediments in the absence of chemical weathering: Effects of abrasion and sorting on bulk composition and mineralogy. Sedimentology 43, 341-358 (1996).

7. S. M. McLennan, S. Hemming, D. K. McDaniel, G. N. Hanson, Geochemical approaches to sedimentation, provenance, and tectonics, in Processes Controlling the Composition of Clastic Sediments, M. J. Johnsson, A. Basu, Eds. Geol. Soc. Amer. Spec. Paper 284, 21-40 (1993).

8. H. W. Nesbitt, G. M. Young, S. M. McLennan, R. R. Keays, Effects of chemical weathering and sorting on the petrogenesis of siliciclastic sediments, with implications for provenance studies. J. Geol. 104, 525-542 (1996).

9. C. M. Fedo, G. M. Young, H. W. Nesbitt, J. M. Hanchar, Potassic and sodic metasomatism in the Southern Provenance of the Canadian Shield: Evidence from the Paleoproterozoic Serpent Formation, Huronian Supergroup, Canada. Precambrian Res. 84, 17-36 (1997).

10. H. W. Nesbitt, Petrogenesis of siliciclastic sediments and sedimentary rocks, in Geochemistry of Sediments and Sedimentary Rocks, D. R. Lentz, Ed. Geol. Assoc. Canada GeoText 4, 39-51 (2003).

11. S. R. Taylor, S. M. McLennan, The Continental Crust: Its Composition and Evolution (Blackwells, Oxford, 1985).

12. S. R. Taylor, S. M. McLennan, Planetary Crusts: Their Composition, Origin and Evolution (Cambridge Univ. Press, Cambridge, 2009).

13. G. M. Young, H. W. Nesbitt, Paleoclimatology and provenance of the glaciogenic Gowganda Formation (Paleoproterozoic), Ontario, Canada: A chemostratigraphic approach. Geol. Soc. Amer. Bull. 111, 264-274 (1999).

14. P. Michalopoulos, R. C. Aller, Rapid clay mineral formation in Amazon Delta sediments reverse weathering and oceanic elemental cycles. Science 270, 614-617 (1995).

15. M. A. Chan et al., Models of iron oxide concretion formation: Field, numerical, and laboratory comparisons. Geofluids 7, 356-368 (2007). 
16. B. C. Clark, et al., Chemistry and mineralogy of outcrops at Meridiani Planum. Earth Planet. Sci. Lett. 240, 73-94 (2005).

17. S. M. McLennan et al., Provenance and diagenesis of the evaporite-bearing Burns formation, Meridiani Planum, Mars. Earth Planet. Sci. Lett. 240, 95-121(2005).

18. J. A. Hurowitz et al., Mixing relationships and the effects of secondary alteration in the Wishstone and Watchtower classes of Husband Hill, Gusev Crater, Mars. J. Geophys. Res.Planets 111, E12S14, doi:10.1029/2006JE002795 (2006).

19. A. H. Knoll et al., Veneers, rinds, and fracture fills: Relatively late alteration of sedimentary rocks at Meridiani Planum, Mars. J. Geophys. Res.-Planets, 113, E06S16, doi:10.1029/2007JE002949 (2008).

20. S. M. McLennan, J. P. Grotzinger, The sedimentary rock cycle of Mars, in The Mars Surface: Composition, Mineralogy and Physical Properties, J. F. Bell III, Ed., pp. 541-577, Cambridge Univ. Press (Cambridge, 2008).

21. S. W. Squyres et al., Ancient impact and aqueous processes at Endeavour crater, Mars. Science 336, 570-576 (2012).

22. B. Ehlmann et al., Subsurface water and clay mineral formation during the early history of Mars. Nature 114, 53-60 (2011).

23. A. Wang et al., Evidence of phyllosilicates in Wooly Patch, an altered rock encountered at West Spur, Columbia Hills, by the Spirit rover in Gusev crater, Mars. J. Geophys. Res. Planets 111, E02S16, doi:10.1029/2005JE002516 (2006).

24. I. O. McGlynn, C. M. Fedo, H. Y. McSween Jr., Soil mineralogy at the Mars Exploration Rover landing sites: An assessment of the competing roles of physical sorting and chemical weathering. J. Geophys. Res. - Planets 117, E01006, doi:10.1029/2011JE003861 (2012).

25. Supplementary materials available on Science Online.

26. A. S. Yen et al., An integrated view of the chemistry and mineralogy of Martian soils. Nature 436, 49-54 (2004).

27. In order to focus on relationships among silicate mineralogy A-CN-K and A-CNK-FM diagrams normally correct $\mathrm{CaO}$ for the presence of carbonates and sedimentary $\mathrm{Ca}$ phosphates $\left(\mathrm{CaO}^{*}\right)$ and in rare cases correct $\mathrm{Na}_{2} \mathrm{O}$ for the presence of halite $\left(\mathrm{Na}_{2} \mathrm{O}^{*}\right)$. In Martian settings attempts at making corrections for chemical constituents have commonly proven non-unique because mineralogical determinations are either incomplete or do not exist and non-silicate mineralogy is both uncertain and complex, involving a variety of Ca-, $\mathrm{Mg}$ - and Fe-sulfates, chlorides, perchlorates and in some cases carbonates. Accordingly, bulk analyses are used in formulating these diagrams and the CIA values and the possibility of non-silicate phases must be considered when making interpretations.

28. M. E. Schmidt et al., APXS of first rocks encountered by Curiosity in Gale Crater: Geochemical diversity and volatile element (K and Zn) enrichment. Lunar Planet. Sci. Conf. 44, Abstract 1278 (2013).

29. K. Stamateloupoulou-Seymour, D. M. Francis, An Archean ultramafic turbidite from Lac Guyer, James Bay area, Quebec, Canada. Can. J. Earth Sci. 17, 1576-1582 (1980). 
30. H. W. Nesbitt et al., Major and trace element geochemistry and genesis of supracrustal rocks of the North Spirit Lake greenstone belt, NW Ontario, Canada. Precambrian Res. 174, 1634 (2009).

31. S. Saha et al., The influence of flood basaltic source terrains on the efficiency of tectonic discrimination diagrams: An example from the Gulf of Khambhat, western Inda. Sediment. Geol. 228, 1-13 (2010).

32. L. L. Griffith, E. L. Shock, Hydrothermal hydration of Martian crust: Illustration via geochemical model calculations. J. Geophys. Res.-Planets 102, 9135-9143 (1997).

33. J. A. Hurowitz et al., Experimental epithermal alteration of synthetic Los Angeles meteorite: Implications for the origin of Martian soils and identification of hydrothermal sites on Mars. J. Geophys. Res.-Planets 110, E07002, doi:10.1029/2004JE002391 (2005).

34. M. V. Naumov, Principal features of impact-generated hydrothermal circulation systems: Mineralogical and geochemical evidence. Geofluids 5, 165-184 (2005).

35. N. J. Tosca et al., Geochemical modeling of evaporation processes on Mars: Insight from the sedimentary record at Meridiani Planum. Earth Planet. Sci. Lett. 240, 122-148 (2005).

36. J. A. Hurowitz et al., In-situ and experimental evidence for acidic weathering on Mars. $J$. Geophys. Res. 111, E02S19, doi:10.1029/2005JE002515 (2006).

37. P. L. King and H. Y. McSween Jr., Effects of $\mathrm{H}_{2} \mathrm{O}, \mathrm{pH}$ and oxidation state on the stability of Fe-minerals on Mars. J. Geophys. Res.-Planets 110, E12S10, doi:10.1029/2005JE002482 (2005).

38. G. M. Young, H. W. Nesbitt, Processes controlling the distribution of Ti and Al in weathering profiles, siliciclastic sediments and sedimentary rocks, J. Sed. Res. 68, 448-455 (1998).

39. N. C. Martinez et al., Local and regional geochemical signatures of surface sediments from the Cariaco Basin and Orinoco Delta, Venezuela, Geology 38, 159-162 (2010).

40. Basaltic Volcanism Study Project, Basaltic Volcanism on the Terrestrial Planets (Pergamon Press, New York, 1981).

41. R. Slingerland, N.D. Smith, Occurrence and formation of waterlaid placers. Ann. Rev. Earth Planet. Sci. 14,113-147 (1986).

42. A. M. Ollila et al., Early results from Gale Crater on ChemCam detections of carbon, lithium, and rubidium. Lunar Planet. Sci. Conf. 44, Abstract 2188 (2013).

43. L.-H. Chan et al., Lithium and lithium isotope profiles through the upper oceanic crust: A study of seawater-basalt exchange at ODP Sites 504A and 896A. Earth Planet. Sci. Lett. 201, 187-201 (2002).

44. F. H. Lu, W. J. Meyers, G. N. Hanson, Trace elements and environmental significance of Messinian gypsum deposits, the Nijar Basin, southeastern Spain. Chem. Geol. 192, 149-161 (2002).

45. E. M. Stolper et al. The petrochemistry of Jake_M: A Martian mugearite. Science 341, 1239463 (2013). 
46. H. Y. McSween et al., Alkaline volcanic rocks from the Columbia Hills, Gusev Crater, Mars. J. Geophys. Res.-Planets 111, E09S91, doi:10.1029/2006JE002698 (2006).

47. H. Nekvasil et al., Linking the Chassigny meteorite and the Martian surface rock Backstay: Insights into igneous crustal differentiation processes on Mars. Meteor. Planet. Sci. 44, 853869 (2009)

48. A. S. Yen et al., Nickel on Mars: Constraints on meteoritic material at the surface. $J$. Geophys. Res.-Planets 111, E12S11, doi:10.1029/2006JE002797 (2006).

49. R. Hutchison, Meteorites: A Petrologic, Chemical and Isotopic Synthesis (Cambridge Univ. Press, Cambridge, 2004).

50. L. J. Suttner, P. K. Dutta, Alluvial sandstone composition and paleoclimate, I. Framework mineralogy. J. Sed. Pet. 56, 329-345 (1986).

51. A. D. Stewart, The ratio of mechanical to chemical denudation in alluvial systems, derived from geochemical mass balance. Trans. Roy. Soc. Edinburgh: Earth Sci. 84, 73-78 (1993).

52. J.-M. Martin, M. Meybeck, Elemental mass-balance of material carried by major world rivers. Marine Chem. 7, 173-206 (1979).

53. I. O. McGlynn, C. M. Fedo, H. Y. McSween Jr., Origin of basaltic soils at Gusev crater, Mars, by aeolian modification of impact-generated sediment. J. Geophys. Res. - Planets 116, E00F22, doi:10.1029/2010JE003712 (2011).

54. H. J. Melosh, Planetary Surface Processes (Cambridge University Press, Cambridge, 2011).

55. N. J. Tosca et al., Physicochemical properties of concentrated Martian surface waters. J. Geophys. Res.-Planets 116, E05004, doi:10.1029/2010JR003700 (2011).

56. S. L. Murchie et al., A synthesis of Martian aqueous mineralogy after 1 Mars year of observations from the Mars Reconnaissance Orbiter. J. Geophys. Res. - Planets 114, 1-30 (2009).

57. J. P. Grotzinger, R. E. Milliken, Eds., Sedimentary Geology of Mars. SEPM Spec. Publ. 12 (Society for Sedimentary Geology, Tulsa, 2012).

58. S. W. Squyres, A. H. Knoll, Eds., Sedimentary Geology at Meridiani Planum, Mars (Elsevier, Amsterdam, 2005)

59. J.-P. Bibring et al., Global mineralogical and aqueous Mars history derived from OMEGA/Mars Express data. Science 312, 400-404 (2006).

60. R. M. Hazen et al., Mineral evolution. Amer. Mineral. 93, 1693-1720 (2008).

61. R. Gellert et al. Initial MSL APXS activities and observations at Gale crater, Mars. Lunar Planet. Sci. Conf. 44, Abstract 1432 (2013).

62. S. Maurice et al., The ChemCam instrument suite on the Mars Science Laboratory (MSL) rover: Science objectives and mast unit description. Space Sci. Rev. 170, 95-106 (2012).

63. R. C. Wiens et al., The ChemCam instrument suite on the Mars Science Laboratory (MSL) rover: Body unit and combined system tests. Space Sci. Rev. 170, 167-227 (2012).

64. D. F. Blake et al., Curiosity at Gale: Characterization and analysis of the Rocknest sand shadow. Science 341, 1239505 (2013). 
65. H. W. Nesbitt, R. E. Wilson, Recent chemical weathering of basalts. Am. J. Sci. 292, 740777 (1993).

66. J. L. Campbell et al., Calibration of the Mars Science Laboratory Alpha Particle X-ray spectrometer. Space Sci. Rev. 170, 319-340 (2012).

67. L. M. Thompson et al., BT-2 calibration target for the Mars Science Laboratory Alpha Particle X-ray spectrometer: Characterization and alkali basalt Martian analogue. Lunar Planet. Sci. Conf. 44, Abstract 2190 (2013).

68. R. Gellert et al., Alpha Particle X-rat spectrometer (APXS): Results from Gusev Crater and calibration report. J. Geophys. Res.-Planets 111, E02S05, doi:10.1029/2005JE002555.

69. R. C. Wiens R.C. et al., Pre-flight calibration and initial data processing for the ChemCam laser-induced breakdown spectroscopy instrument on the Mars Science Laboratory rover. Spectrochim. Acta B82, 1-27 (2013).

70. S. M. Clegg et al., Quantitative remote laser induced breakdown spectroscopy by multivariate analysis. Spectrochim. Acta B64, 79-88 (2009).

71. S. Le Mouelic et al., Mars imaging by the ChemCam remote microscopic imager (RMI) onboard Curiosity: The first three months. Lunar Planet. Sci. Conf. 44, Abstract 1213 (2013).

72. M. H. Reed et al., Users Guide for CHIM-XPT (University of Oregon, 2010).

Acknowledgments: Much of this research was carried out at the Jet Propulsion Laboratory, California Institute of Technology, under contract with NASA. Development and operation of the ChemCam and APXS instruments were also supported by funds from the French Space Agency, CNES and the Canadian Space Agency. Organizations supporting research include NASA, the Canadian Space Agency and NSERC (Canada) and the United Kingdom Space Agency (UK). Chemical data presented here are derived from archived data sets in the NASA Planetary Data System (PDS) http://pds-geosciences.wustl.edu/missions/msl/. We are grateful to the MSL engineering and management teams for making the mission and this scientific investigation possible and to science team members who contributed to mission operations. The senior author (SMM) thanks Lamont-Doherty Earth Observatory of Columbia University, and especially Sidney Hemming, for hospitality during a sabbatical when the manuscript was being prepared. 

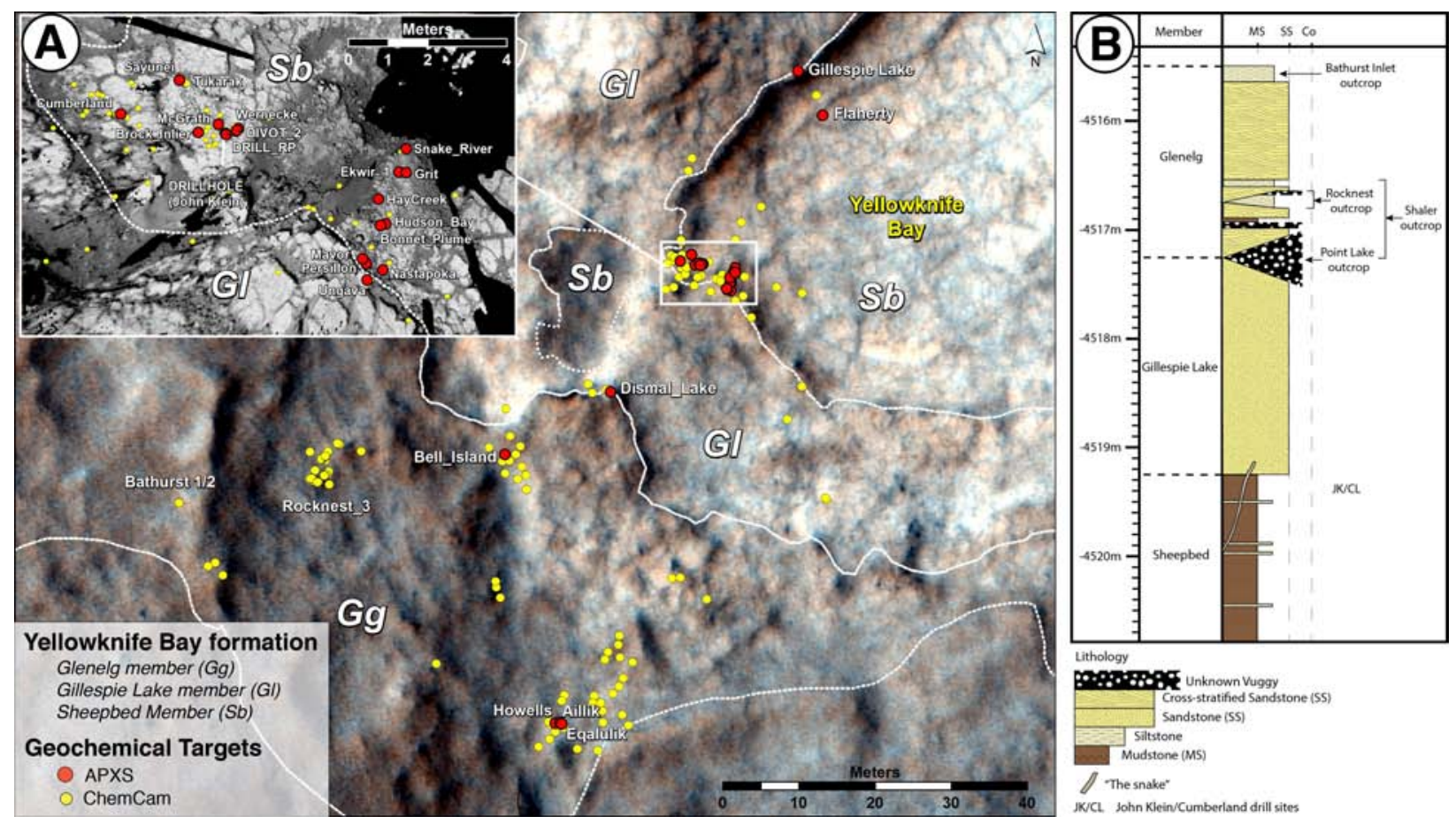

Fig. 1. Geological context and locations of analyses. (A) HiRISE image (part of PSP_010573_1755) showing geological relationships of the Yellowknife Bay formation, location and names of APXS analyses, locations of ChemCam LIBS analyses, and names of ChemCam targets, Tukarak and McGrath (also an APXS target), discussed in the text. Inset shows expanded Navigational camera overhead projection of the region where drilling of the Sheepbed member took place (John_Klein and Cumberland) and where the Selwyn Section (targets between Snake_River and Ungava) was examined. Additional details about sample locations, including the ChemCam target names, are shown in Figs. S1-S7. (B) Stratigraphic section of the Yellowknife Bay formation at Yellowknife Bay. Also shown is the stratigraphic relationship of the cross-cutting dike-like feature termed "the snake" (adapted from ref. 2). 

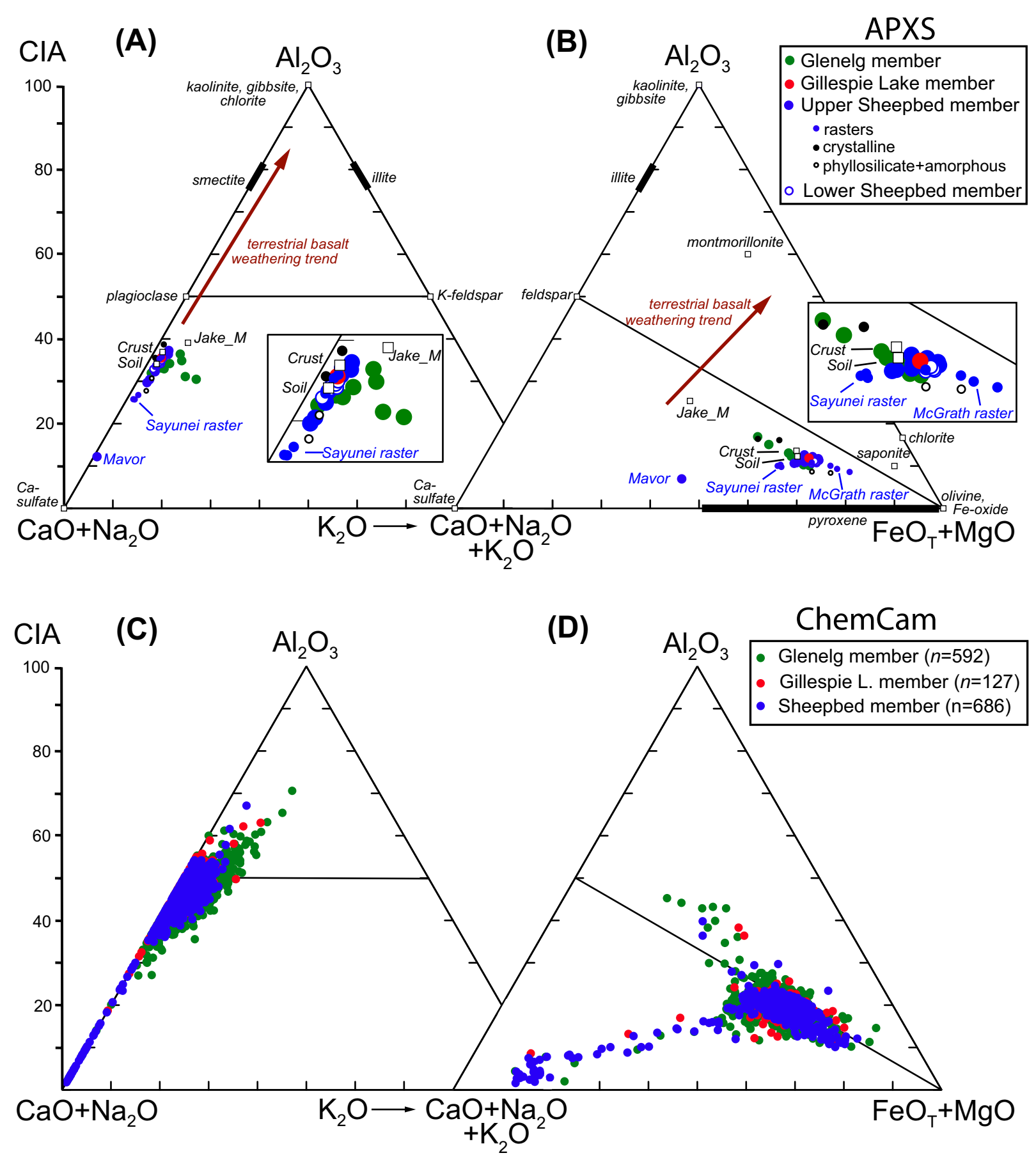

Fig. 2. $\mathrm{Al}_{2} \mathrm{O}_{3}-\left(\mathrm{CaO}+\mathrm{Na}_{2} \mathrm{O}\right)-\mathrm{K}_{2} \mathrm{O}$ and $\mathrm{Al}_{2} \mathrm{O}_{3}-\left(\mathrm{CaO}+\mathrm{Na}_{2} \mathrm{O}+\mathrm{K}_{2} \mathrm{O}\right)-\left(\mathrm{FeO}_{\mathrm{T}}+\mathrm{MgO}\right)$ ternary diagrams. (A,B) APXS data; (C,D) ChemCam data. Shown for reference are the CIA scale (measured on (A) and (C) only), and, as open squares, average Martian crust (12), local soil (64) and the local rock Jake_Matiijevic (Jake_M) (45), modeled compositions of John_Klein and Cumberland crystalline and clay+amorphous materials (4), and arrows representing typical trends observed for terrestrial weathering profiles on basalts (65). The insets of (A) and (B) are expanded views of the main cluster of data. 


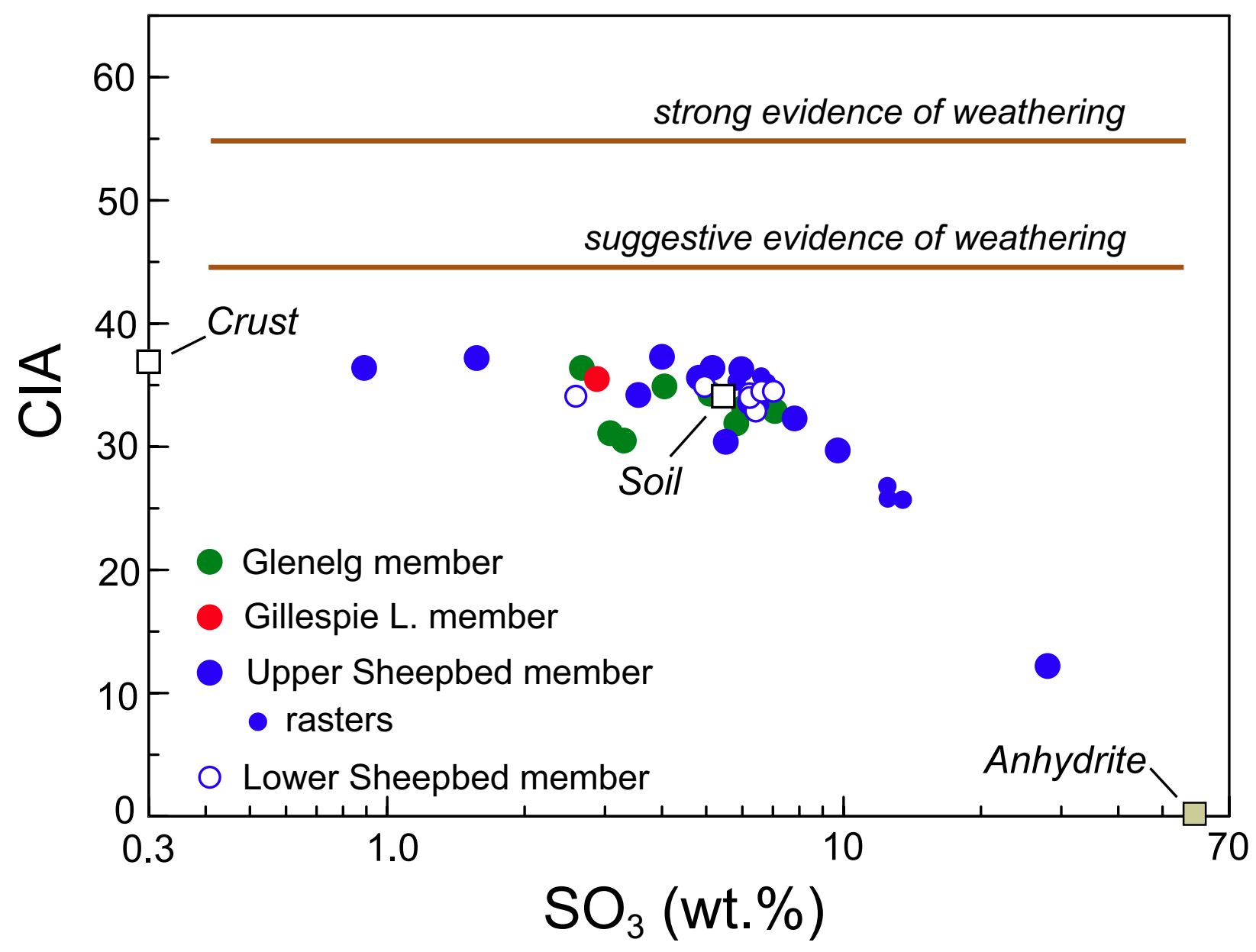

Fig. 3. Plot of CIA versus $\mathrm{SO}_{3}$ contents for Yellowknife Bay formation APXS analyses. Shown for reference, as open squares, are average Martian crust (12), local soil (64), the composition of anhydrite $\left(\mathrm{CaSO}_{4}\right)$ and horizontal lines that show the CIA values expected for basaltic sedimentary rocks that have experienced a chemical weathering history. 

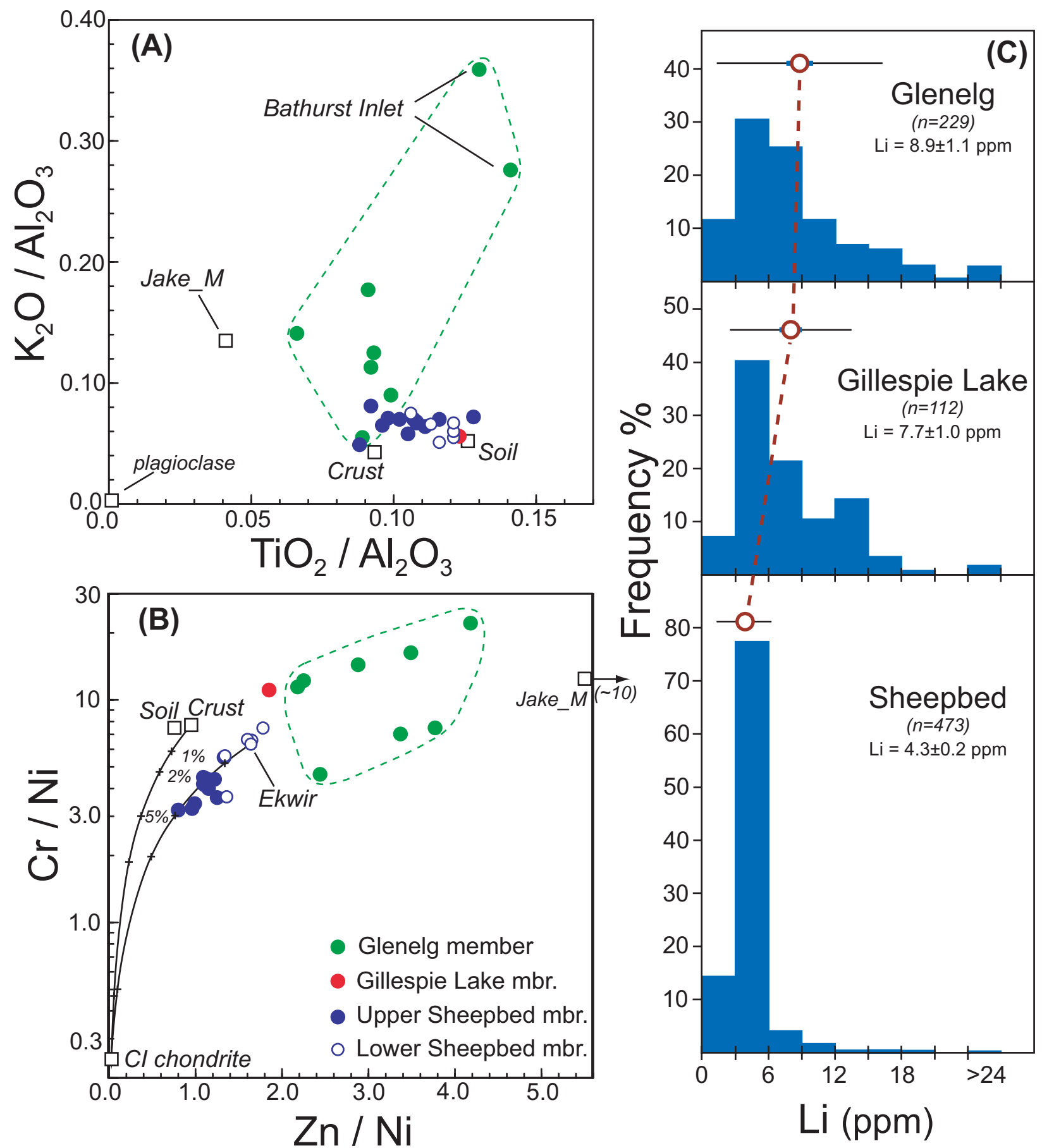

Fig. 4. Geochemical relationships within the Yellowknife Bay formation highlighting stratigraphic variations. (A) APXS K $20 / \mathrm{Al}_{2} \mathrm{O}_{3}$ versus $\mathrm{TiO}_{2} / \mathrm{Al}_{2} \mathrm{O}_{3}$; (B) APXS Cr/Ni versus $\mathrm{Zn} / \mathrm{Ni}$; (C) histograms of ChemCam Li abundances also showing mean (red circle), standard deviation (black bar) and 95\% confidence interval (blue bar; also the uncertainty reported on the averages). In Figures 4A and 4B the compositions of average Martian crust (12), local soil (64), the rock Jake_Matijevic (45), average CI chondrite (12) and plagioclase are shown for reference. Also shown on Fig. 2B are mixing lines between average Martian crust and the Ekwir_Brush target and average CI chondrite. 

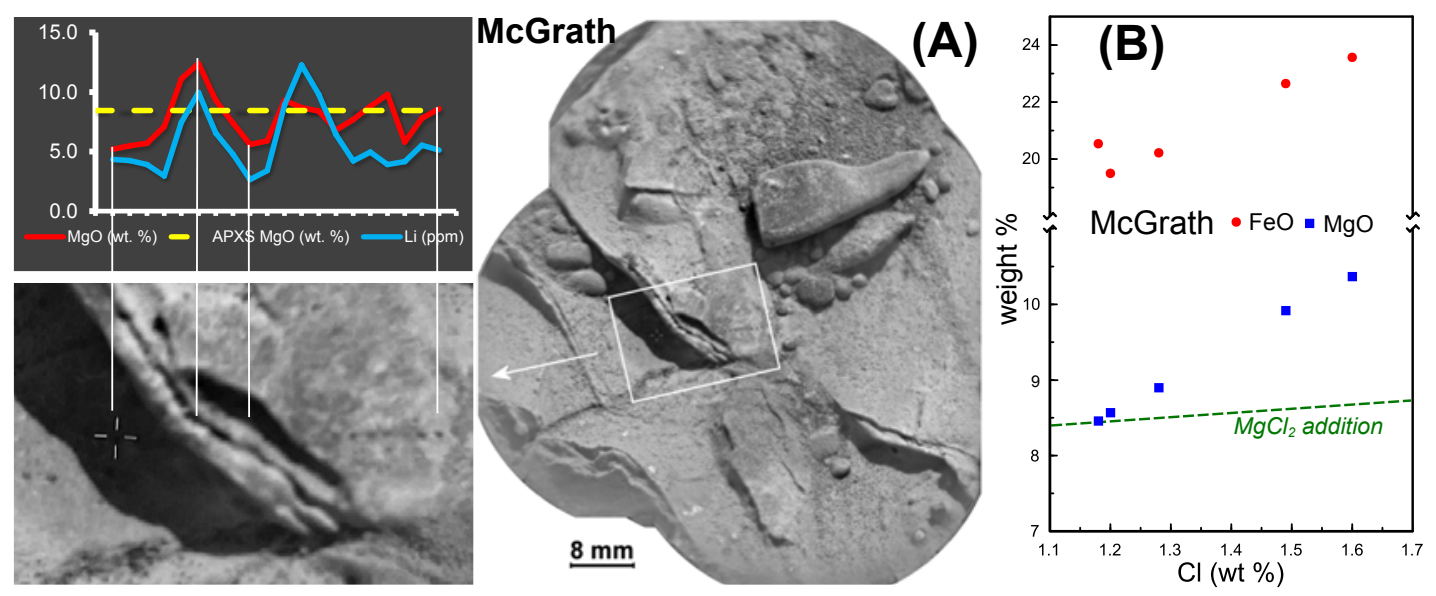

(C)

(D)

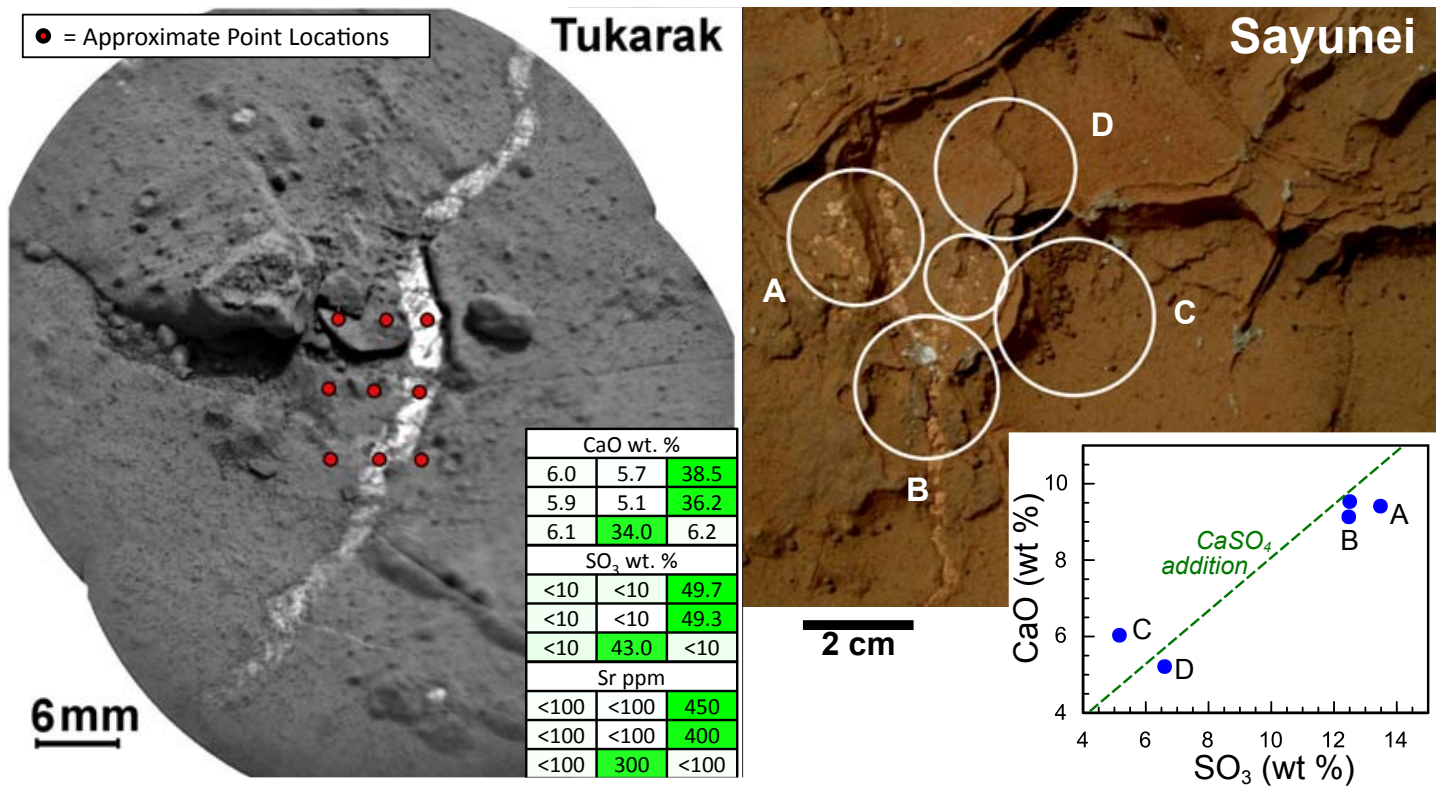

Fig. 5. Geochemical constraints on diagenetic features within the Yellowknife Bay formation. (A) ChemCam RMI image of the McGrath target "raised ridge" that is dipping gently to the upper right. Inset shows LIBS $\mathrm{MgO}$ and $\mathrm{Li}$ transects for 20 shots taken a cross the feature. Shown for reference is the average MgO of McGrath, determined by APXS. Note elevated and correlated $\mathrm{Mg}$ and $\mathrm{Li}$ at the site of the raised ridge. Also note that elevated $\mathrm{Mg}$ (but not $\mathrm{Li}$ ) is observed on the right hand side that likely represents the outer layer of the cement, exposed on the dipping surface. (B) APXS raster analysis for McGrath showing elevated Fe and $\mathrm{Mg}$ that correlate with $\mathrm{Cl}$. Note the break in the scale on the $\mathrm{y}$-axis. A model of $\mathrm{MgCl}_{2}$ addition is shown to illustrate that the correlation is not due simply to the presence of chloride phases. (C) ChemCam RMI image of a late diagenetic light-toned fracture at the Tukarak target. Location of a 3x3 LIBS raster is shown and results for $\mathrm{Ca}, \mathrm{S}$ and $\mathrm{Sr}$, relative to their position in the raster, are given in the inset table. (D) APXS raster analysis on late diagenetic light-toned fracture at the Sayunei target. Inset shows plot of $\mathrm{CaO}$ versus $\mathrm{SO}_{3}$ with a model illustrating the effects of $\mathrm{CaSO}_{4}$ addition. 


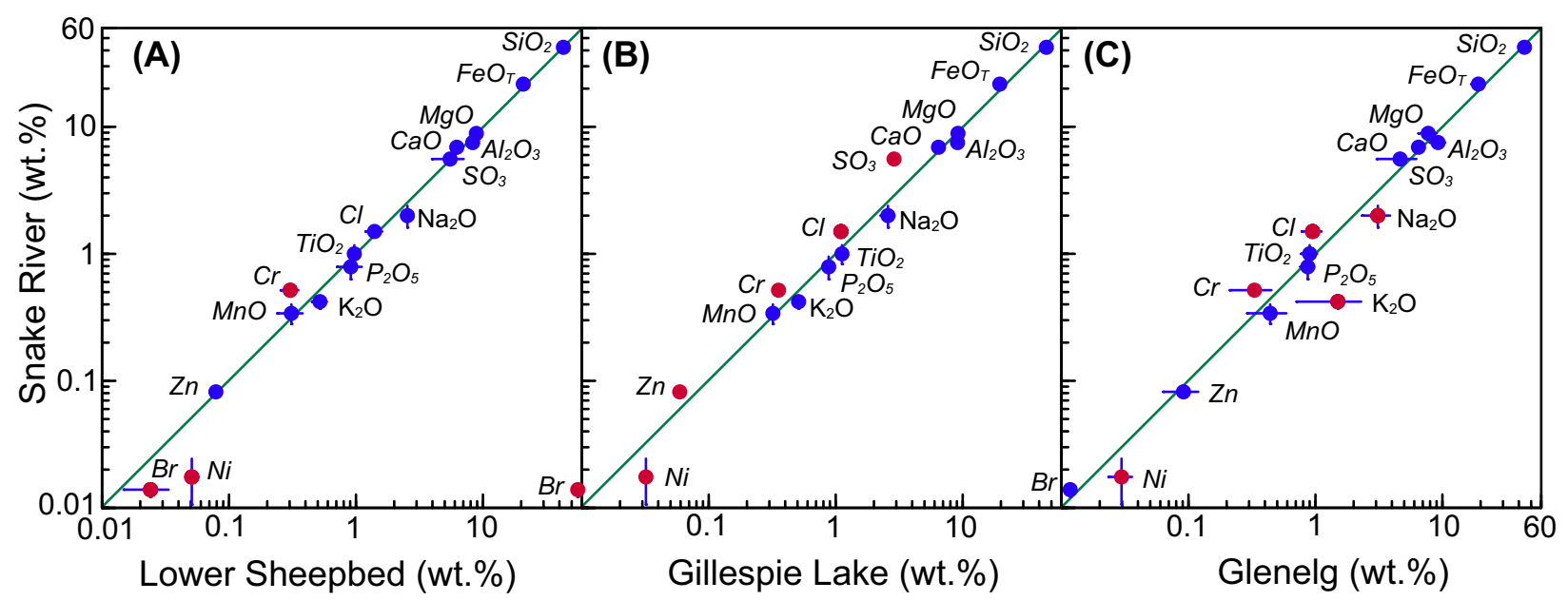

Fig. 6. Comparison diagrams for the dike-like feature, termed the "snake". APXS composition of the Snake_River target compared to (A) lower Sheepbed member average, (B) Gillespie Lake member sample and (C) Glenelg member average. The upper Sheepbed is not used for this comparison because compared to the lower Sheepbed, its geochemistry is more heavily influenced by diagenetic features (e.g., Ca-sulfate veins, concretions). The diagonal green line represents equal compositions. Error bars (if larger than the symbol size) represent two sigma errors for individual samples (Snake_River, Gillespie Lake) and one standard deviation on the mean for averages (Lower Sheepbed member, Glenelg member). Significant differences in composition are shown as red symbols.

\section{Supplementary Materials:}

Materials and Methods

Figures S1-S8

Tables S1-S8

MSL Science Team Author List

References (66-72) 


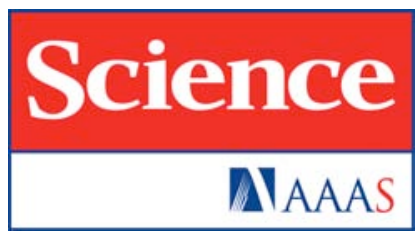

\section{Supplementary Materials for}

\section{Elemental Geochemistry of Sedimentary Rocks at Yellowknife Bay, Gale Crater, Mars}

S. M. McLennan*, R. B. Anderson, J. F. Bell III, J. C. Bridges, F. Calef III, J. L.

Campbell, B. C. Clark, S. Clegg, P. Conrad, A. Cousin, D. J. Des Marais, G. Dromart, M. D. Dyar, L. A. Edgar, B. L. Ehlmann, C. Fabre, O. Forni, O. Gasnault, R. Gellert, S. Gordon, J. A. Grant, J. P. Grotzinger, S. Gupta, K. E. Herkenhoff, J. A. Hurowitz, P. L. King, S. Le Mouélic, L. A. Leshin, R. Léveillé, K. W. Lewis, N. Mangold, S. Maurice, D. W. Ming, R. V. Morris, M. Nachon, H. E. Newsom, A. M. Ollila, G. M. Perrett, M. S. Rice, M. E. Schmidt, S. P. Schwenzer, K. Stack, E. M. Stolper, D. Y. Sumner, A. H. Treiman, S. VanBommel, D. T. Vaniman, A. Vasavada, R. C. Wiens, R. A. Yingst, MSL Science Team

*Corresponding author. Email: Scott.McLennan@stonybrook.edu

\section{This PDF file includes:}

Materials and Methods

Figs. S1 to S8

Tables S1 to S8

MSL Science Team Author List 


\section{Materials and Methods}

APXS Methods

The MSL APXS uses radioactive ${ }^{244} \mathrm{Cm}$ sources that excite geologic samples via PIXE ("particle-induced X-ray emission") and XRF (X-ray fluorescence). Characteristic $\mathrm{X}$-rays are emitted from the sample as a result of these two processes and are detected by the APXS instrument. The characteristic X-ray energies are unique for each element and their intensities are used to determine the weight fraction abundances of major, minor, and some trace $(\mathrm{Cr}, \mathrm{Ni}, \mathrm{Zn}, \mathrm{Br}, \mathrm{Ge})$ elements $(61,66)$. Penetration depths to the region above which $90 \%$ of the observed $X$-rays originate increase as a function of $Z$ and range from 2 to $80 \mu \mathrm{m}$ for $\mathrm{Na}$ to Fe. A calibration standard (67) was sent to Mars with the rover to verify that the APXS calibration produced on Earth remains valid on Mars. A Peltier cooler permits the recording of daytime spectra with integrations as short as 10 minutes. An aluminum contact sensor allows for reproducible instrument placement heights, which is valuable for determining accurate elemental abundances. In some instances, the position relative to the rover or the nature of the targeted geological material required stand-off distances of $1-3 \mathrm{~cm}$ in response to complexity of arm movement, or to prevent contamination of the APXS sources by fine-grained materials (i.e., tailings pile).

The APXS data reported here (Tables S1-S4) were reduced using an empirical peakfitting and calibration routine that was developed for the Mars Exploration Rover (MER) APXS analyses (68). Varying stand-off distances are taken into account by a geometric normalization such that the total oxide content is normalized to $100 \mathrm{wt} \%$. Statistical $(2 \sigma)$ errors were generated by the respective spectrum-fitting routines; these errors are functions of the overall spectral intensity and thus reflect duration and stand-off, and they are also increased by increasing temperature which causes greater peak overlap. These are summarized for the reported samples in Table S7. Statistical errors are significantly smaller than the analytical uncertainties. Rock mineralogy and microscopic heterogeneity limits the accuracy of the APXS analysis approach that is used since it assumes a homogeneous sample. Current best estimates of overall analytical accuracies based on powdered geological reference materials are $\sim \pm 3 \%$ (relative) for $\mathrm{Si}, \pm 5-10 \%$ for $\mathrm{Al}, \mathrm{Ca}$, $\mathrm{Mn}$ and $\mathrm{Fe}, \pm 10-15 \%$ for $\mathrm{Na}, \mathrm{P}, \mathrm{S}$ and $\mathrm{K}, \pm 15-20 \%$ for $\mathrm{Mg}, \mathrm{Ti}, \mathrm{Cr}, \mathrm{Ni}, \mathrm{Zn}, \mathrm{Ge}$ and $\mathrm{Br}$, and $\sim \pm 30 \%$ for $\mathrm{Cl}(66)$. In addition to the general limitations of the method there are unknown effects such as dust cover or small-scale layering that can obscure especially the lighter elements in the analysis. Statistical errors are used in the discussion since they represent the uncertainties on the relative changes of elemental abundances and inferred mineralogical abundances among the samples. One sample analyzed from the Gillespie Lake member (Ungava) has very large analytical $2 \sigma$ errors (up to $> \pm 50 \%$ relative for some elements including $\mathrm{Na}, \mathrm{P}$ and $\mathrm{Ni}$ ) due to short integration times and high temperatures and is not reported or discussed here.

Of the bedrock targets examined by the APXS at Yellowknife Bay (Fig. 1, Fig. S1), only two (Ekwir and Wernecke) were brushed by the Dust Removal Tool (DRT). Thus all other rock targets are variably covered with fine-grained dust and soil, and reported rock compositions contain contributions from both dust and the underlying rock. Dust contamination most affects $\mathrm{S}$ and $\mathrm{Cl}$ concentrations because these elements are enriched in Martian dust $\left(\mathrm{SO}_{3} / \mathrm{Cl} 9 ; 12,26,68\right)$. In addition, the X-rays for the lightest elements 
detected by the APXS (Na, Mg, and Al) are largely contributed by the outer $2-3 \mu \mathrm{m}$ of the target and thus surface dust coatings $>4 \mu \mathrm{m}$ can block and/or contribute X-rays that combine with those from the underlying rock (28). As such, brushing of the Wernecke target resulted in a significant decrease in $\mathrm{SO}_{3}(5.6$ to $0.9 \mathrm{wt} \%$ ) and a slight increase in $\mathrm{Na}_{2} \mathrm{O}(2.7$ to $3.0 \mathrm{wt} \%)$.

\section{ChemCam Methods}

For ChemCam LIBS data each target was interrogated with between 5 and 25 observation points arranged in a line or in a rectangular grid covering the object of interest. At every observation point ChemCam obtained a spectrum with each of 30 laser shots, profiling into the rock or soil. For each of the observation points, the first five spectra were discarded to avoid contamination by surficial dust. The remaining 25 active spectra from each observation point were averaged and a set of 30 background spectra taken on the same targets without the laser were averaged and subtracted from the mean active spectra. The data were preprocessed as described in Wiens et al. (69). The continuum was removed, the spectra were de-noised, and an instrument optical response correction was applied. From there, data were processed separately for the major elements, the trace elements, and for sulfur.

The major element weight fraction abundances were determined using a partial least squares (PLS) multivariate approach in which a regression model is produced correlating the LIBS spectra and the corresponding elemental compositions of a training set of reference standards (e.g. ref. 70). For this work an algorithm was used known as PLS1 in which only one element is regressed at a time. The spectral training set was taken with the ChemCam flight unit prior to delivery (69). The number of components, or latent variables, was adjusted to minimize the root mean square error product (RMSEP) determined by the cross-validations of the model. As some of the major elements only have significant emission lines in one of the three spectrometers, they are optimized differently in terms of the normalization step that precedes PLS1 processing. For some elements the normalization was carried out separately on the ranges from each spectrometer instead of normalizing the entire emission spectrum. These are indicated by a " 3 " in the normalization line in Table S8. Statistics on compositional distribution of the training set, the number of principal components used to fit each element, and the resulting RMSEP are also given in Table S8. Absolute errors of the Mars data, e.g., due to any Earth-to-Mars differences in spectra, may be different from the training set cross validation, but differences likely do not expand this error envelope. Point-to-point precision of the ChemCam LIBS data was shown in the laboratory to generally be factors of 5-20 better than the RMSEP (69). Calcium abundances given for Tukarak in Fig. 5 were obtained using PLS1 but with slight differences in the training set and parameters to specifically address calcium sulfates.

Due to the low intensity of the sulfur emission lines in the LIBS spectrum, $\mathrm{S}$ abundances were determined separately. To maximize efficiency for these emission lines, the emission from all channels within a local maximum were summed and placed into the channel representing the maximum. This peak-area spectrum was then processed using PLS1 against a training set containing all sulfur-bearing standards from Wiens et al. (69). RMSEPs were determined from cross-validation of the training set, as above, and 
indicate that $\mathrm{S}$ abundances are accurate to approximately $\pm 20 \%$ relative for $\mathrm{SO}_{3}$ abundances $>10 \%$ (e.g., $\mathrm{SO}_{3}=10 \pm 2 \mathrm{wt} \%$ ).

Lithium abundances were determined using a univariate peak area linear regression approach with a training set of references standards that are generally a subset of those listed in Wiens et al. (69). The RMSEP is $40 \mathrm{ppm}$, and is calculated in the same manner as the major elements. Strontium abundances were determined from modified PLS1 models. The PLS1 method is similar to that described for the major elements but instead of using a large wavelength range, the model only inputs the wavelengths that are strongly correlated to $\mathrm{Sr}$ in the training set, and are known to be emissions from $\mathrm{Sr}$ transitions. This reduces the likelihood that $\mathrm{Sr}$ will be estimated solely on major element correlations. Two models were developed for $\mathrm{Sr}$ because the chemical matrix affected $\mathrm{Sr}$ to a fairly significant degree and samples with an igneous or igneous-like suite of major elements were placed in one model and all samples, including sulfates, carbonates and Al-clays were placed in a second model. The igneous matrix model has an RMSEP of $160 \mathrm{ppm}$ and the all-samples model has an RMSEP of $430 \mathrm{ppm}$. The Sr in the ChemCam analysis points that analyzed Ca-sulfate vein material were estimated using the allsamples model while points on the surrounding igneous-like matrix were estimated using the igneous matrix model.

ChemCam includes a Remote Micro-Imager (RMI) to provide context images of the targets at a resolution of approximately 40 micro-radians. Images are typically taken before the first LIBS point and after the last one of a given target. If the spacing between the first and last LIBS points is too large to be covered in two images, additional images are taken during the course of the LIBS observations. Image mosaics can be produced that show the surface in question either before or after the LIBS interrogation by using the appropriate parts of each image in the mosaic. The RMI images are corrected for flat field, bad pixels, ghost images, and background using standard routines (71).

For this work ChemCam observed 154 targets (Fig. 1, Figs, S1-S7), which contained a total of 1,454 individual LIBS observation points consisting of approximately 45,000 spectra. To support these spectral observations approximately $400 \mathrm{RMI}$ images were taken. These data are too numerous to present the individual analyses and images here, so the reader is referred to the ChemCam archives in the Planetary Data System (http://pdsgeosciences.wustl.edu/missions/msl/).

\section{Mass Balance Calculations}

We carried out several mass balance calculations to better constrain the nature of the diagenetic phases and a possible meteoritic contribution to the Sheepbed member of the Yellowknife Bay formation.

Concretion compositions. We attempted to constrain the composition of the spherules, interpreted to be sedimentary concretions (2). The two drill holes at the targets John_Klein and Cumberland were selected to evaluate the composition of the spherules with Cumberland being in an area with more spherules and the target itself having a higher abundance of spherules+hollow nodules. There are numerous analyses at each drill site but we chose to use the drill fines, those that accumulated on the surface during the drilling process, for comparison. The drill powders actually delivered to and analyzed by CheMin and SAM and then dumped onto the Martian surface would be better but at the time of writing, Curiosity was still carrying the Cumberland sample and accordingly, no 
APXS analysis was available. We carried out a two-step model. First, the equivalent of $5 \% \mathrm{Ca}$-sulfate as anhydrite was removed from the John_Klein analysis, an amount chosen to put $\mathrm{SO}_{3}$ abundances at similar levels in both analyses and to be consistent with vein mapping in the drill hole (4). After this correction, a gain $(+) / \operatorname{loss}(-)$ constant oxide mass balance was calculated:

$$
\Delta C^{j} / C^{i}(\%)=100 *\left[\frac{C_{s}^{j} / C_{s}^{i}}{C_{p}^{j} / C_{p}^{i}}-1\right]
$$

where $C$ is concentration in weight percent or ppm, superscripts $j$ and $i$ are element of interest and an "immobile" element respectively, and subscripts $s$ and $p$ are sample of interest (Cumberland) and reference sample (John_Klein) respectively.

Two calculations were carried out by assuming that in one case Al was "immobile" and in the other case that Ti was "immobile. Elements enriched in Cumberland by $>5 \%$ in both calculations included $\mathrm{Fe}, \mathrm{Ca}, \mathrm{Cl}, \mathrm{Br}, \mathrm{Ni}$ and $\mathrm{Ge}$. Elevated $\mathrm{Ca}$ is difficult to interpret given the $\mathrm{Ca}$-sulfate fractures but elevated $\mathrm{Fe}, \mathrm{Cl}, \mathrm{Br}$ and $\mathrm{Ni}$ are consistent with small amounts of a minor mineral such as akaganeite, identified by XRD, forming the concretion cement (4). Calculations are summarized in Table S5.

Cements in diagenetic fractures ("raised ridges"). Raised ridges are characterized by isopachous banding along the margins of the fractures, which could be the location of cementing agents. ChemCam first identified high $\mathrm{MgO}$ associated with raised ridges and this was confirmed by APXS rater analysis on the target McGrath, which further indicated elevated $\mathrm{Fe}$ and that both $\mathrm{Mg}$ and $\mathrm{Fe}$ correlate with $\mathrm{Cl}$. In order to constrain the composition of the Mg-rich component we carried out a series of mass balance calculations using the highest and lowest APXS MgO analyses from the McGrath raster (McGrath-R1 and McGrath-R2). The composition of the phase/assemblage was calculated by increasing the proportion of the Mg-rich component in increments of 5\% until all elements, except for $\mathrm{Ca}, \mathrm{S}$ and $\mathrm{K}$, were positive in the $\mathrm{Mg}$-rich component (Table S6), using the formula:

$$
\mathrm{C}_{\text {Mg-component }}=\left[\mathrm{C}_{M c \text { Grath-R2 }}-(1-x) \mathrm{C}_{M c \text { Grath-R1 }}\right] / x
$$

where $\mathrm{C}_{M g \text {-component }}, \mathrm{C}_{M c G r a t h-R 1}$ and $\mathrm{C}_{M c \text { Grath-R2 }}$ are the concentrations of an element in the $\mathrm{Mg}$-rich component, McGrath-R1 and McGrath-R2 respectively and $x$ is the proportion of the Mg-rich phase in McGrath-R2. Ca and S were neglected because of the possibility of variable Ca-sulfate veining and $\mathrm{K}$ was neglected because its concentration is low and variable among the McGrath raster samples. The optimum point was reached when the component constituted $20 \%$ of McGrath-R2, and for these conditions, indicates a composition for the $\mathrm{Mg}$-rich component of $\mathrm{SiO}_{2} \sim 46 \%$; $\mathrm{FeO}_{\mathrm{T}} \sim 36 \%$;gO $18 \%, \mathrm{Cl} 3 \%$ and 1,300-1,500 ppm each for Ni, Zn and Br. Such a composition cannot be accommodated by any single phase identified in the drill holes by XRD (4), but perhaps consistent with a mixture of Mg-rich, Al-deficient smectitic clay (e.g., hectorite, stevensite) and Cl-bearing Fe-oxides (e.g., akaganeite).

Meteoritic component in the Sheepbed member. Planetary soils from the Moon and Mars show evidence for meteoritic components, typically on the order of $\sim 2-3 \%$ (12) and an ancient fine-grained lacustrine sedimentary rock deposited in a distal facies of an 
alluvial fan on Mars could also be a site where meteoritic material might accumulate. Of the elements analyzed at Yellowknife Bay, nickel is by far the most sensitive for evaluating meteoritic components and the effects of mixing a $\mathrm{CI}$ chondritic composition was evaluated in Fig. 4B using a simple mixing calculation of the form:

$$
\mathrm{C}_{\text {mix }}=x \mathrm{C}_{C I}+(1-x) \mathrm{C}_{\text {sample }}
$$

where $\mathrm{C}_{\text {sample }}, \mathrm{C}_{C I}$ and $\mathrm{C}_{\text {mix }}$ are the concentrations of an element in the starting sample (Martian crust or Ekwir_brush), average CI chondrite and the mixture respectively and $x$ is the proportion of $\mathrm{CI}$ chondrite in the mixture. Mixing components and $\mathrm{Cr}, \mathrm{Ni}$ and $\mathrm{Zn}$ concentrations used in the calculations were:

(1) Average Martian crust (12). Note that this estimate of the Martian crust is based in part on average Martian soils and a 2\% meteoritic component is subtracted. The composition of this end member is: $\mathrm{Cr}=2600 \mathrm{ppm} ; \mathrm{Zn}=320 \mathrm{ppm} ; \mathrm{Ni}=337 \mathrm{ppm}$.

(2) Lower Sheepbed member sample Ekwir_brush. This sample was selected because it is the only brushed sample in the lower Sheepbed member and thus is least contaminated by surface soils and dust. The composition of this end member is: $\mathrm{Cr}=$ 3051 ppm; $\mathrm{Zn}=789$ ppm; $\mathrm{Ni}=482 \mathrm{ppm}$.

(3) Average CI chondritic meteorite was taken to represent average meteoritic material, although we recognize that different classes of meteorites could have different levels of these elements. The composition used is the average of those tabulated in Taylor and McLennan (12), and the composition used was: $\mathrm{Cr}=2653 \mathrm{ppm} ; \mathrm{Zn}=317 \mathrm{ppm}$; $\mathrm{Ni}=10,900 \mathrm{ppm}$.

Preliminary Thermochemical Modeling of Diagenesis at Yellowknife Bay

The Yellowknife Bay formation has undergone at least two diagenetic events associated with phyllosilicate and magnetite formation (4) and then Ca-sulfate formation (2). We demonstrate that geochemical modeling can be used to support these observations and puts constraint on the water to rock ratios as well as the newly formed alteration minerals and the water composition during the diagenesis. We used CHIMXPT (72) for our model.

Figure S8 shows alteration minerals forming from a rock of Ekwir_Brushed APXS composition (Table S1) at different water to rock ratios. The water to rock ratio $(\mathrm{W} / \mathrm{R})$ is a measure of the amount of water that reacted with the rock (i.e., for this work, W/R is defined as the mass ratio of water to dissolved rock). This has to be distinguished from the amount of water that was present. For example, at a W/R of 100 , if only $10 \%$ of the rock reacted, it would imply a ratio of total water to total rock of 10 . This is best illustrated by the observation of low salinity (2) and thus high complementary W/R during deposition of the Yellowknife Bay formation. However, at the same time olivine remains present in at least some of the sedimentary rocks e.g. the John_Klein drill sample (4). This shows that there is unreacted rock in the system, and therefore a relatively low total volume of water was present in the total volume of reacted plus unreacted rock.

We consider 3 different W/R scenarios (in all cases, water activity is held constant): very high W/R (>12000), intermediate W/R (1000-300) and low W/R $(<100)$. At very high $\mathrm{W} / \mathrm{R}$, chlorite is formed alongside an iron oxide (the exact iron oxide mineralogy depends strongly on the redox state of the rock and temperature, which are insufficiently 
constrained, and accordingly we refer only to generic iron oxide-hydroxide). Note, that any precipitate at this $\mathrm{W} / \mathrm{R}$ is only present in very small abundances, because very small amounts of rock react with the water. In light of the low overall volume of water, finding such alteration products seems unlikely, because their frequent occurrence would require more water than the observations support. At intermediate W/R the situation is different, because more precipitate is formed, and in a rock of Ekwir_Brushed bulk composition dominated by Fe-smectite clay (equivalent to nontronite in our model), with up to $35 \%$ of chlorite. At low W/R chlorite becomes the dominating alteration product, accompanied by iron oxides, quartz and talc. Pyroxene will not form for kinetic reasons. Note that true chlorite was not identified by XRD of drill samples but there may be a chlorite-like component in the phyllosilicate interlayers and the XRD data are further consistent with the presence of incipient chlorite (4).

The most important scenario in the case of Yellowknife Bay is probably the intermediate W/R (Fig. S8), because it supports the link between W/R and salinity of the fluid, and is consistent with the saponite-chlorite and iron oxide found by CheMin (4). In fact, the fluid in equilibrium with the alteration assemblage at a W/R of 1000 contains 0.09 moles of dissolved species per $\mathrm{kg}$ of water. The most abundant species are $\mathrm{Cl}, \mathrm{Mg}$, $\mathrm{SO}_{4}$, and $\mathrm{Ca}$, in their order of decreasing abundance. If this fluid is separated from the site of reaction (e.g. into fractures) then water removal (by cooling and subsequent freezing and/or evaporation) would lead to silica precipitation followed by phosphate and sulfate - the latter identified in the late veins. The modeled solution thereby changes from neutral to more acidic $\mathrm{pH}$ and would also be capable of secondary reactions, such as local corrosion of sulfides, predicted in our model, to akaganeite (4) that have not previously reacted.

It is important to note that only a few model runs (and only one of which is shown here) could never entirely explain the range of mineralogical and geological observations at Yellowknife Bay. Here we focused our preliminary modeling primarily on the formation of smectitic clay and the model result is nevertheless consistent with the mineralogy observed in the Sheepbed mudstones. This provides a complementary technique to comparing the Sheepbed major element trends with those predicted to result from weathering, which we primarily use in this paper. 


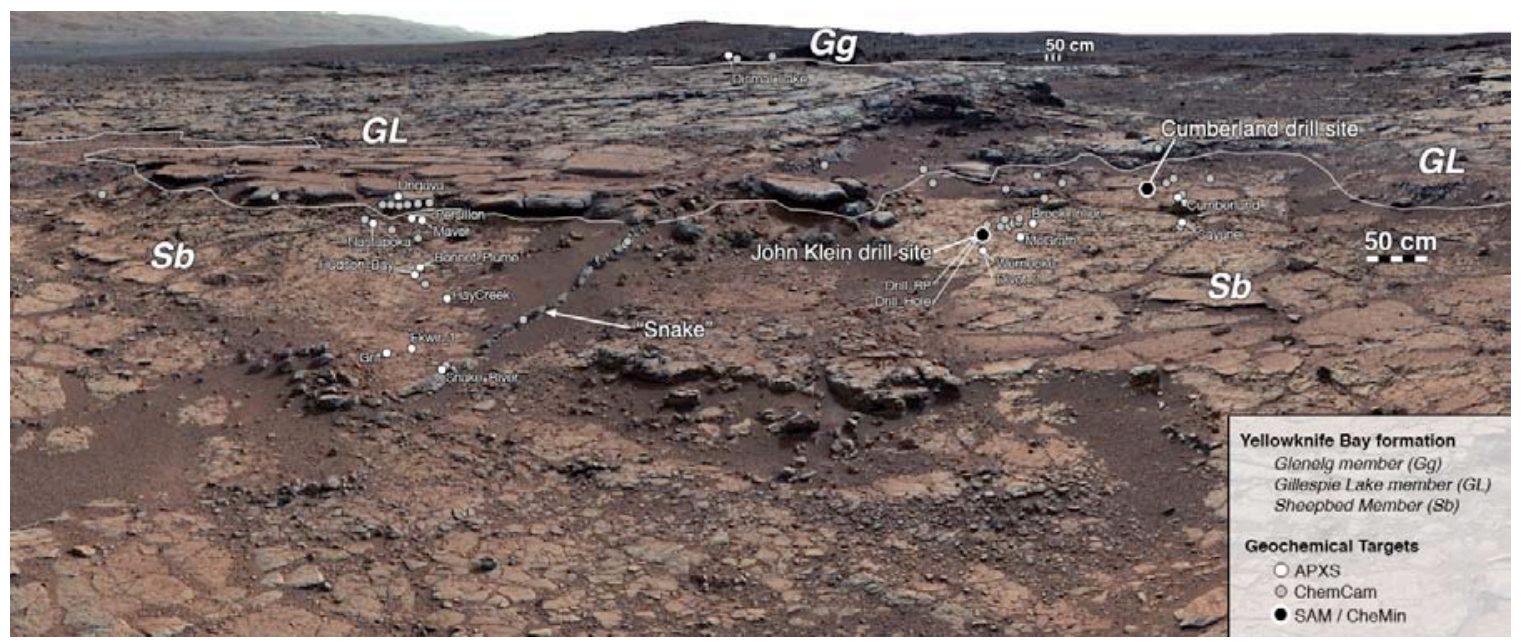

Fig. S1.

Mastcam mosaic of Yellowknife Bay formation with locations of visible APXS (white dots; including target names) and ChemCam targets (grey dots) from Fig. 1. Also shown are APXS targets where drilling and SAM and CheMin (XRD) measurements were made (black dots) and approximate locations of contacts between the Sheepbed, Gillespie Lake and Glenelg members. View from base of exposed section through the Sheepbed, Gillespie Lake and Glenelg members. Both scale bars are 50 centimeters long with 10 centimeter spaces; the lower scale is about 8 meters from the Curiosity rover position and the upper scale bar is about 30 meters away. The mosaic was acquired on sol 137 by the Mastcam-34 camera, sequence 818 (modified from Fig. 3 in ref. 2). 


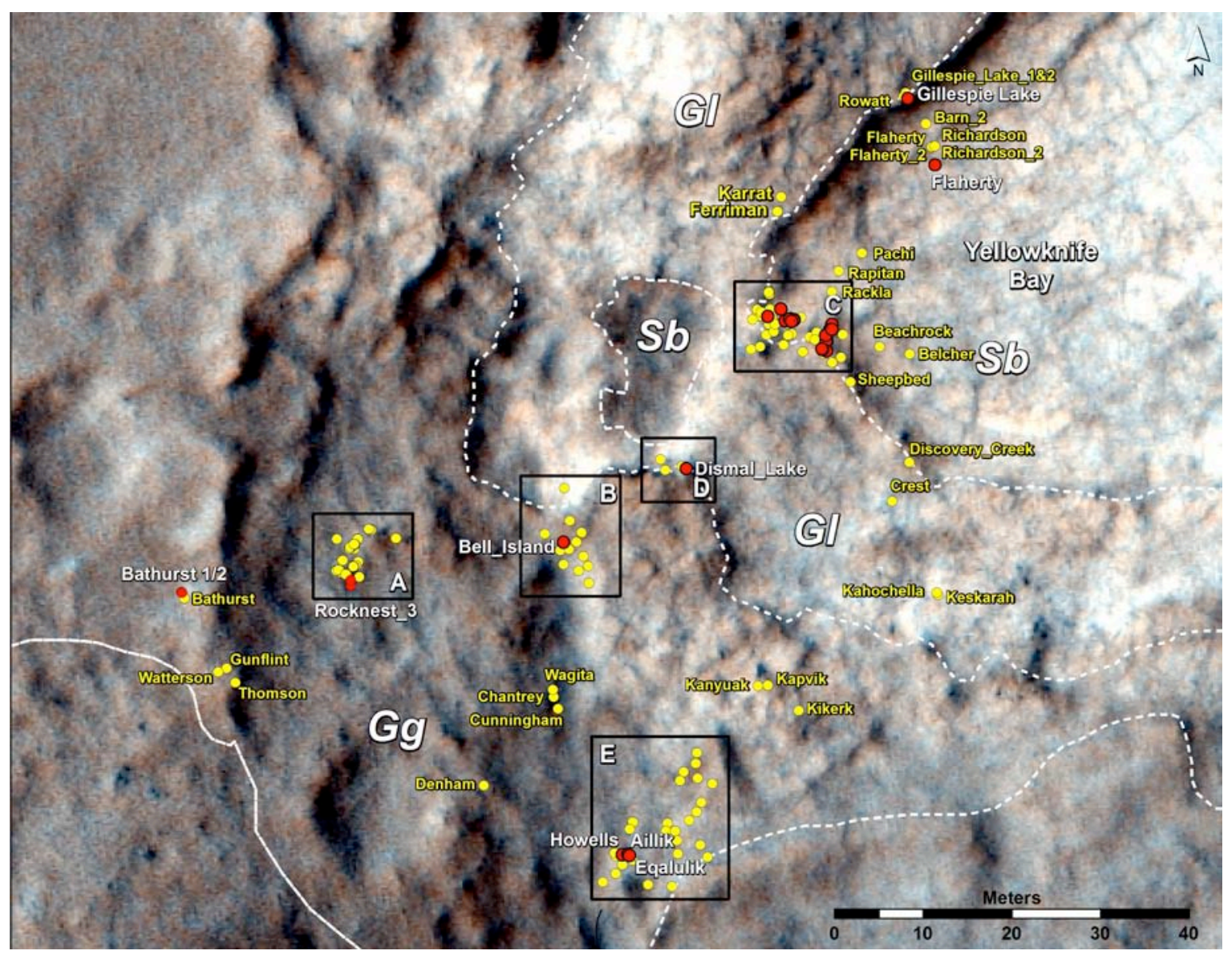

Fig. S2

HiRISE image (part of PSP_010573_1755) taken at $25 \mathrm{~cm} /$ pixel showing geological relationships of the Yellowknife Bay formation (see Fig. 1 for legend) and location and names of ChemCam targets as yellow dots with yellow lettering. Red dots are APXS locations with several showing the target names in white lettering for reference (see Fig. 1 and Fig. S1 for complete information on APXS target locations and names). Boxes A$\mathrm{E}$ are regions represented in Figs. S3-S7. 


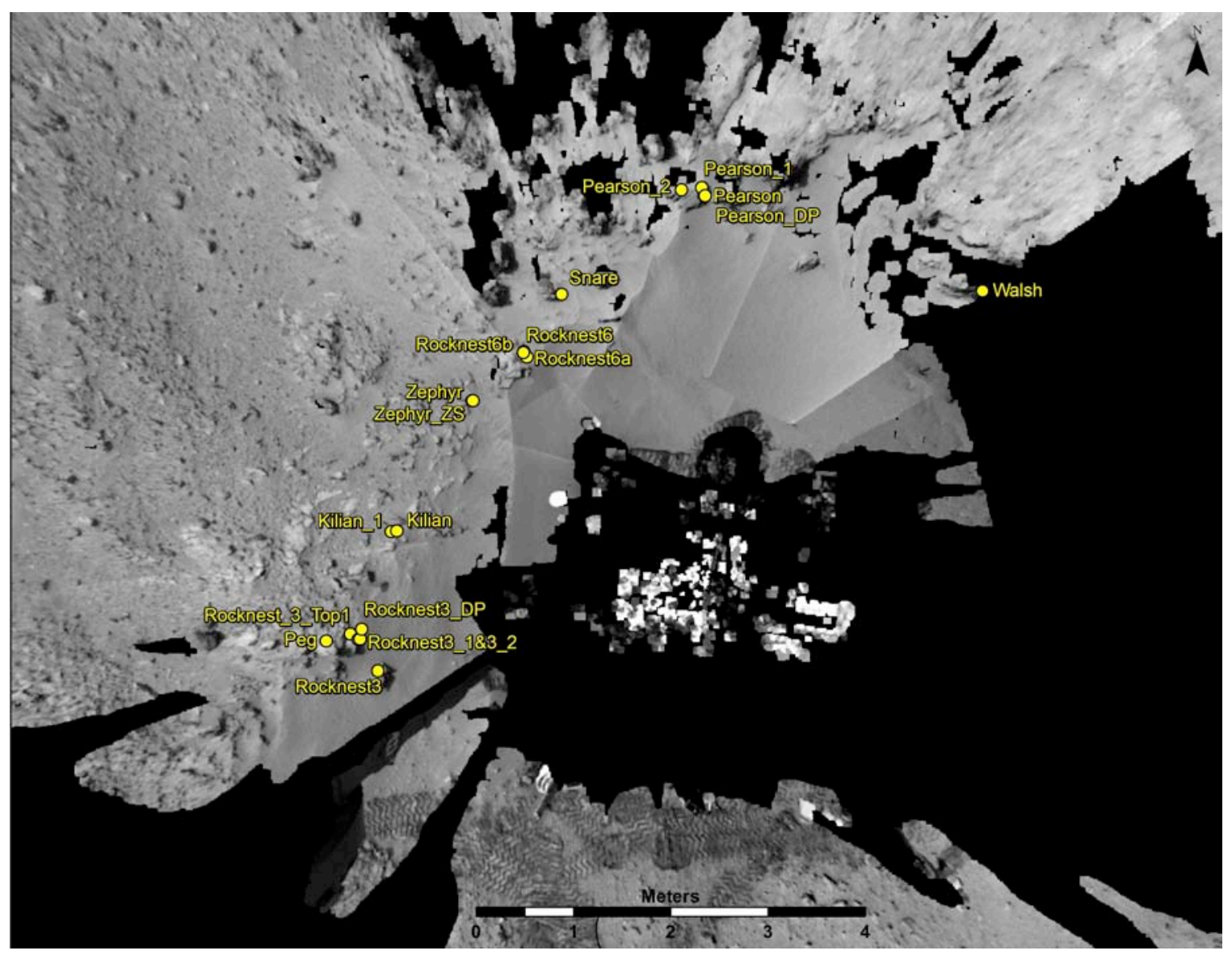

Fig. S3

Location and names of ChemCam targets in Area A of Fig. S2. Image is an overhead Navigational Camera projection taken at $1 \mathrm{~cm} /$ pixel. 


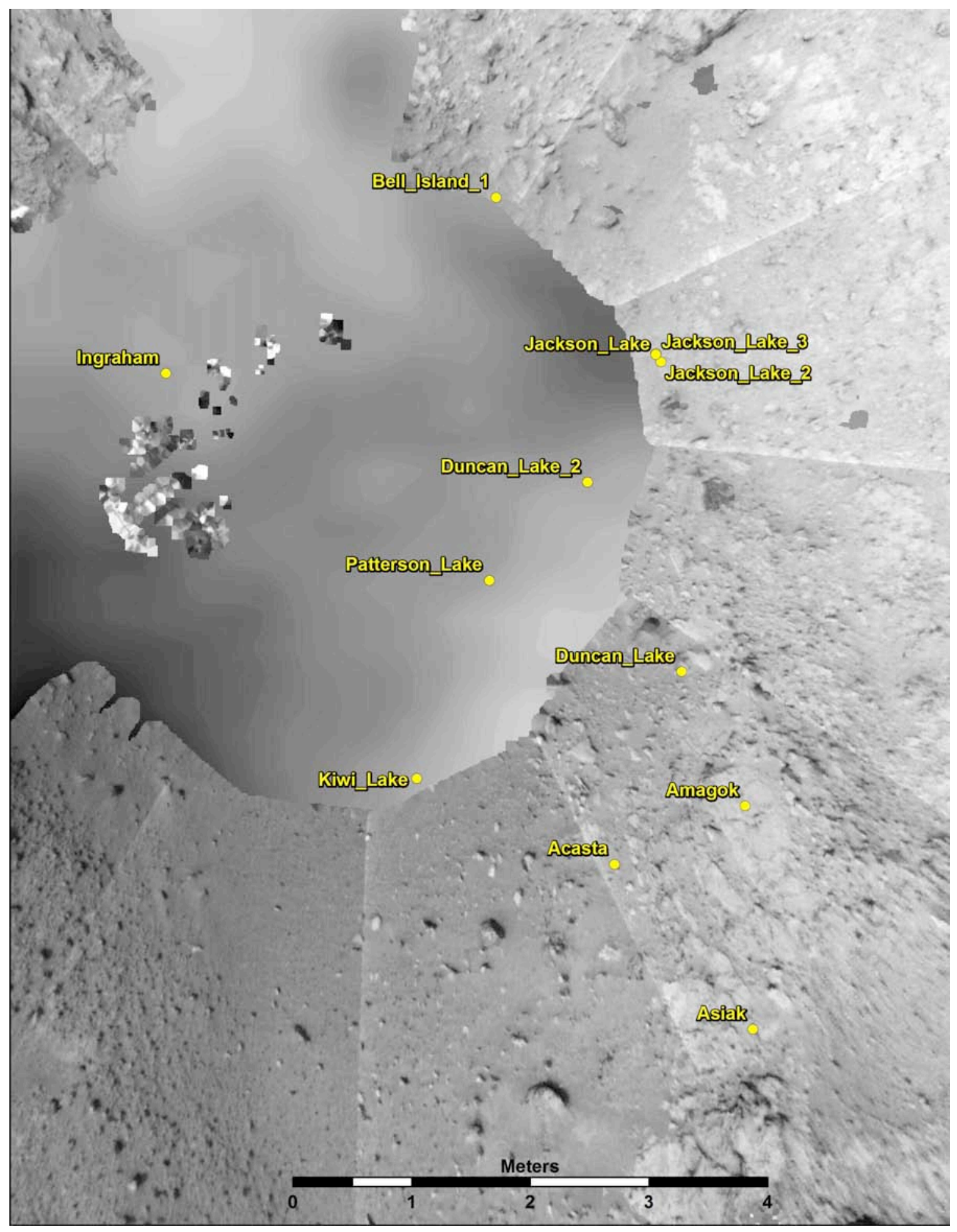

Fig. $\mathbf{S 4}$

Location and names of ChemCam targets in Area B of Fig. S2. Image is an overhead Navigational Camera projection taken at $1 \mathrm{~cm} /$ pixel. 


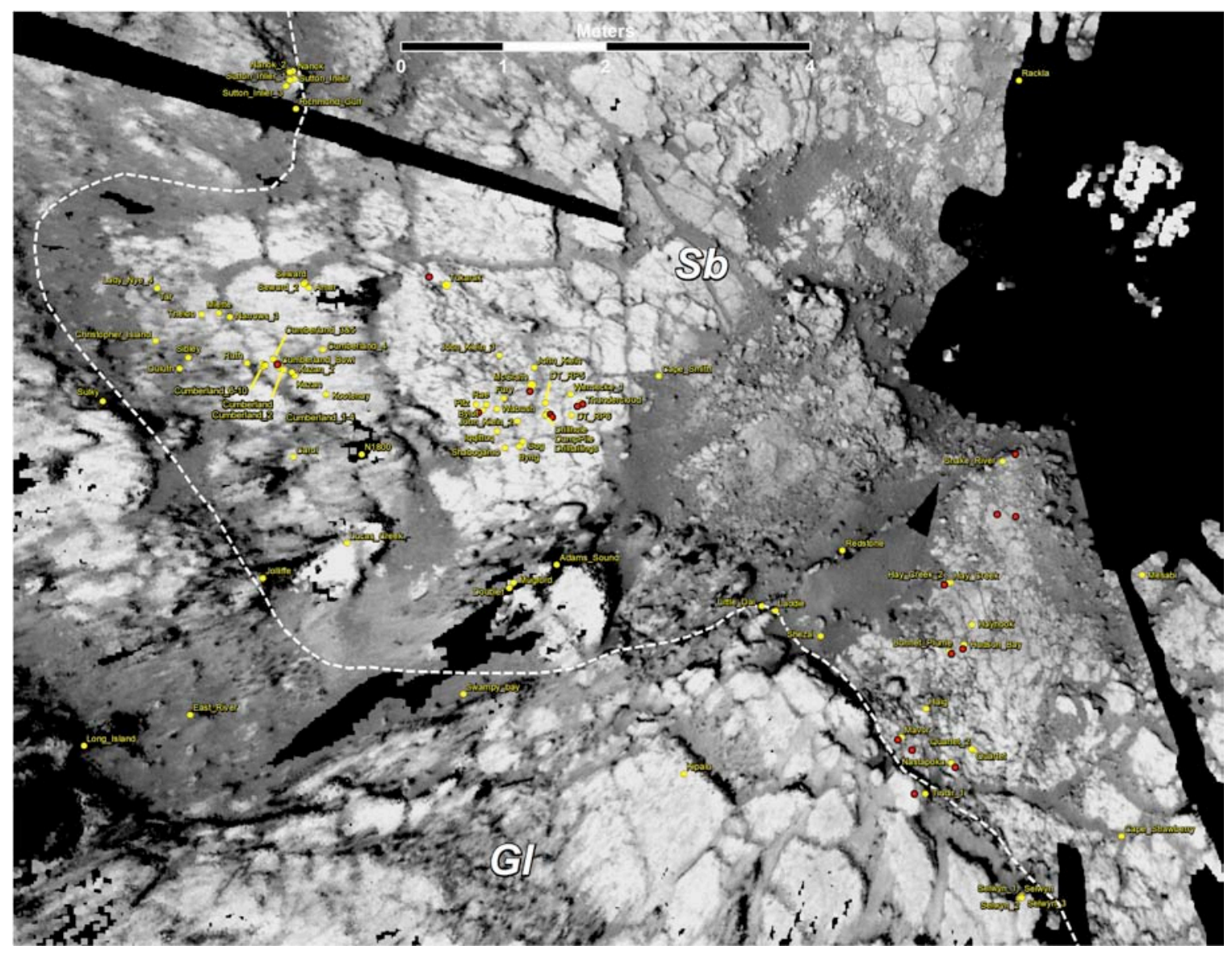

Fig. $\mathbf{S 5}$

Location and names of ChemCam targets in Area C of Fig. S2. Image is an overhead Navigational Camera projection taken at $1 \mathrm{~cm} /$ pixel. Red dots are selected APXS target locations (see Fig. 1 and Fig. S1 for further details of APXS target locations and names). 


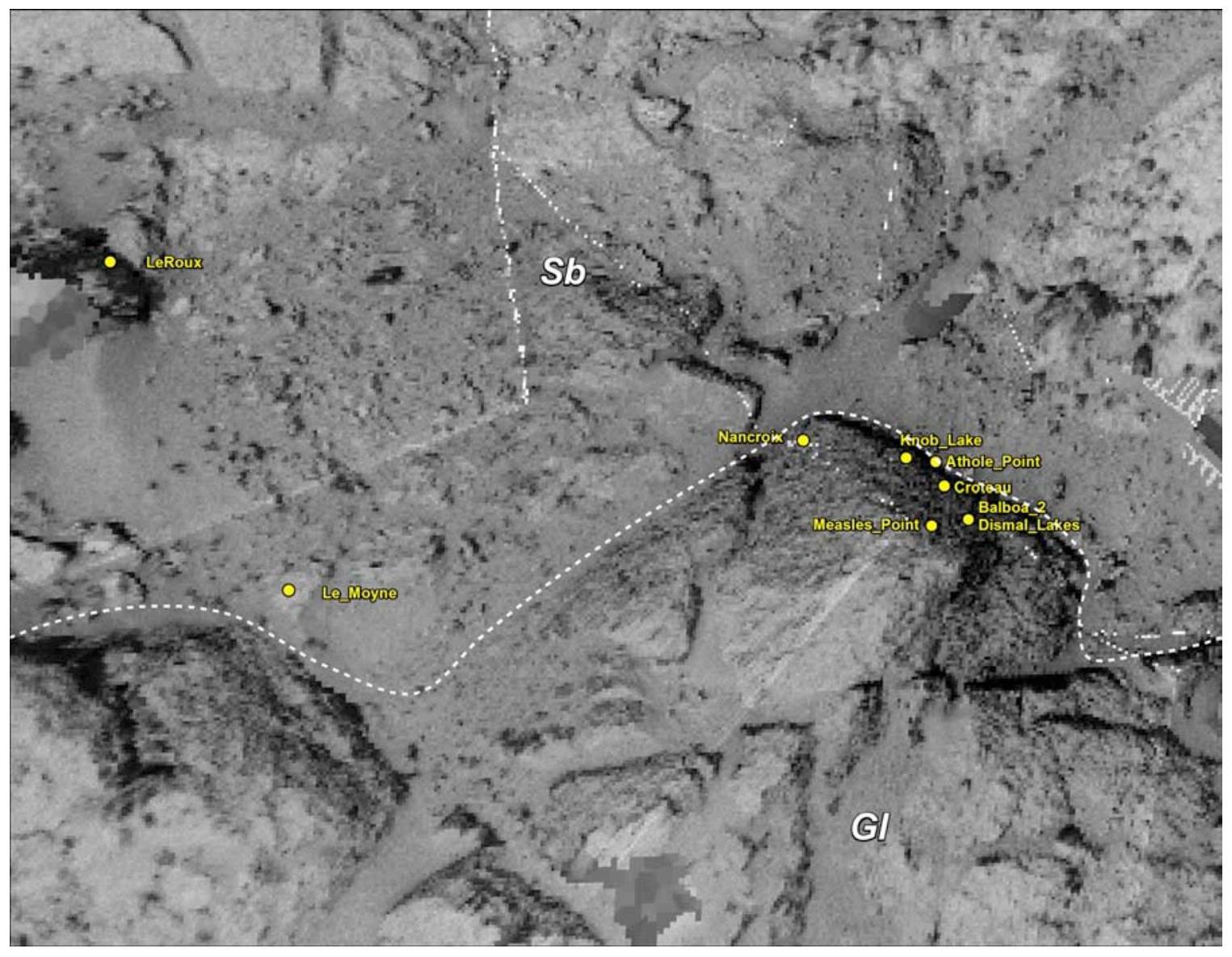

Fig. S6

Location and names of ChemCam targets in Area D of Fig. S2. Image is an overhead Navigational Camera projection taken at $1 \mathrm{~cm} /$ pixel. 


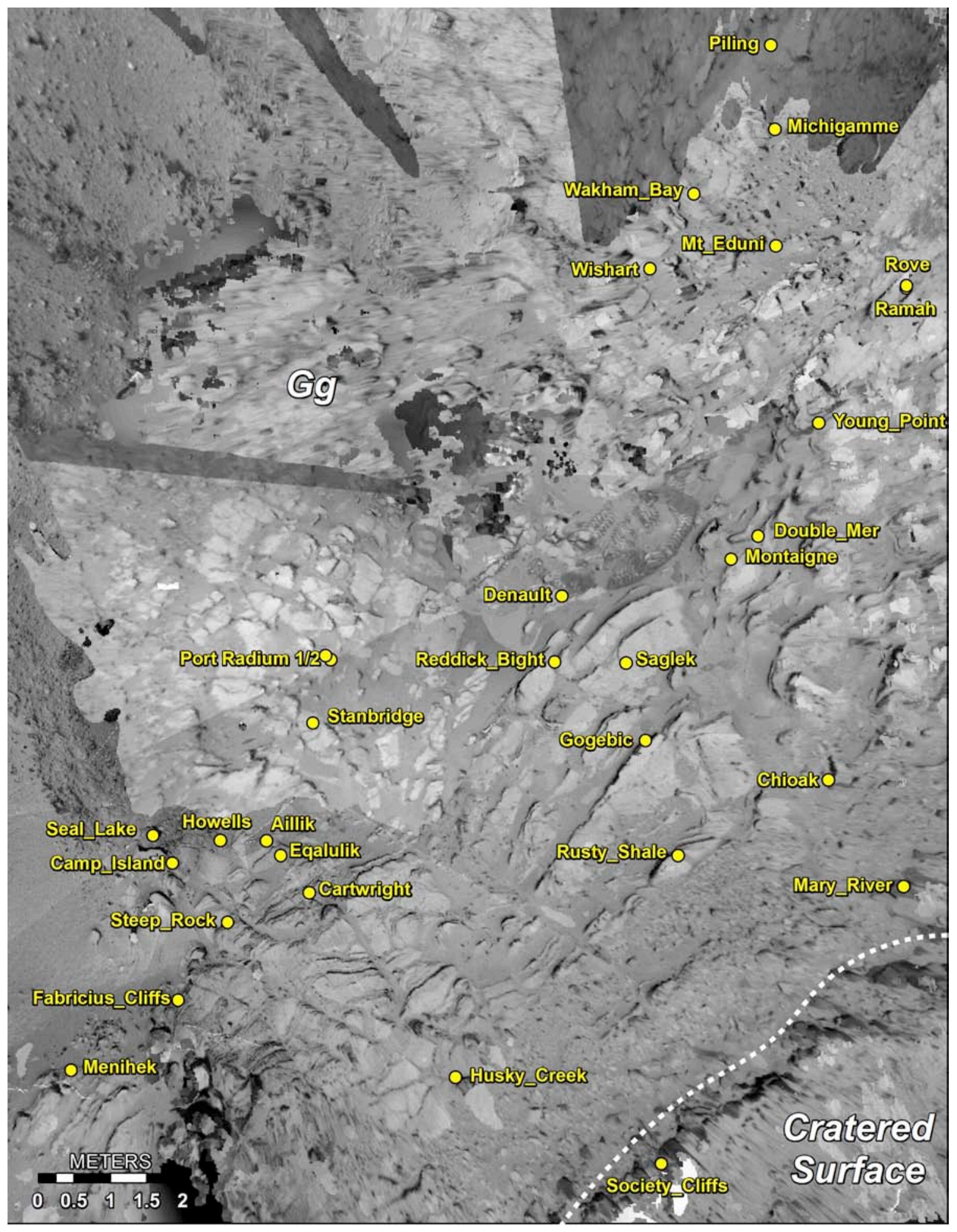

Fig. $\mathbf{S 7}$

Location and names of ChemCam targets in Area E of Fig. S2. Image is an overhead Navigational Camera projection taken at $1 \mathrm{~cm} /$ pixel. 
Ekwir modeled at $25^{\circ} \mathrm{C}$ and 1 bar
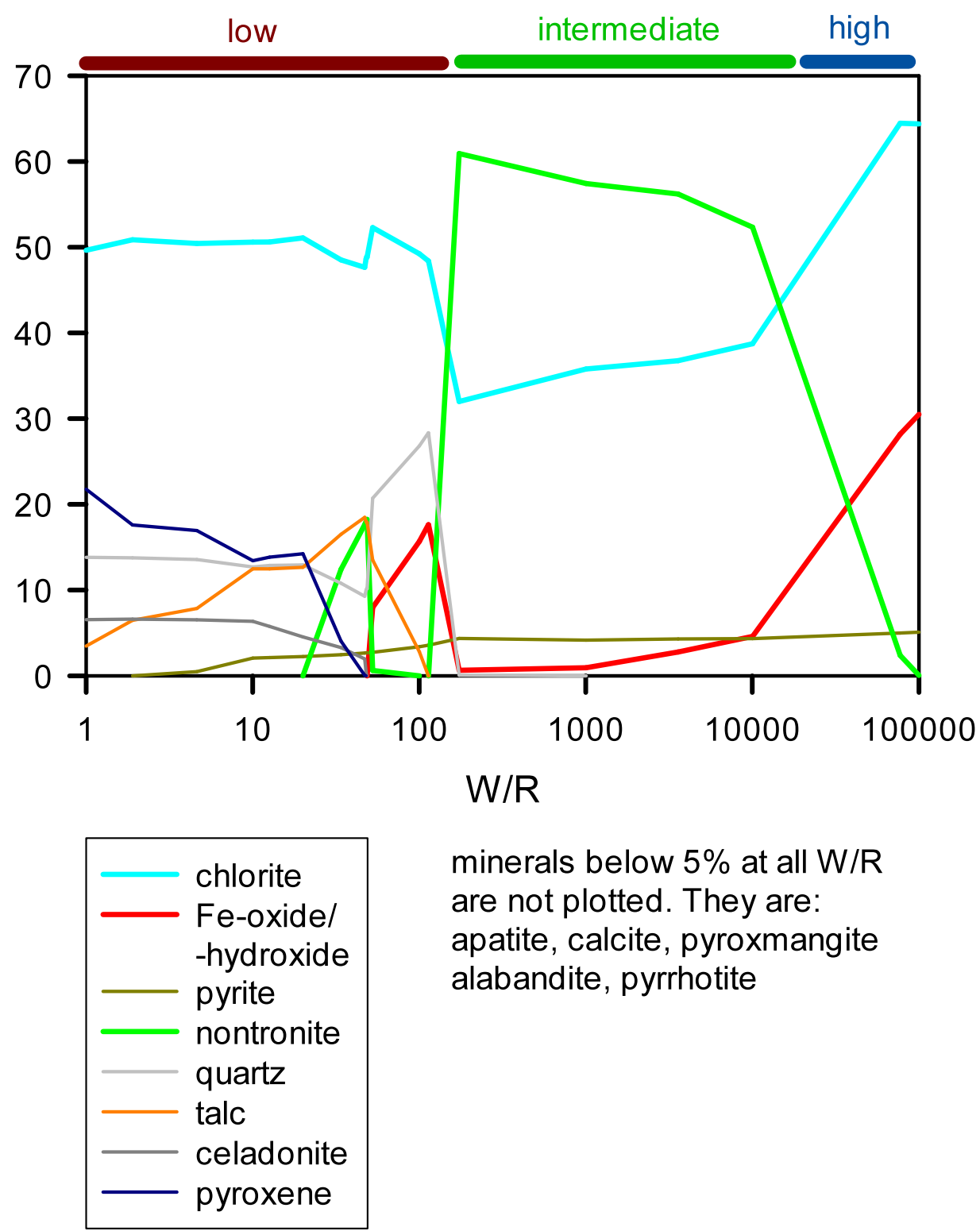

minerals below $5 \%$ at all W/R are not plotted. They are:

apatite, calcite, pyroxmangite

alabandite, pyrrhotite

Fig. S8

Alteration minerals that occur from a reaction of Ekwir_Brush APXS composition rock with water. Water to rock ratio (W/R) is the mass of rock that has reacted with the fluid (see text). The intermediate $\mathrm{W} / \mathrm{R}$ is most consistent with the CheMin analyses of John_Klein and Cumberland (4). 
Table S1.

APXS analyses of the lower part of the Sheepbed member listed in approximate stratigraphic order from the base (major elements in wt \%, trace elements in ppm).

\begin{tabular}{|c|c|c|c|c|c|c|}
\hline & Flaherty & Costello & Grit & $\begin{array}{c}\text { Ekwir_1 } \\
\text { Brush }\end{array}$ & $\begin{array}{l}\text { Hay__ } \\
\text { Creek }\end{array}$ & $\begin{array}{c}\text { Hudson } \\
\text { Bay }\end{array}$ \\
\hline $\mathrm{SiO}_{2}$ & 41.3 & 42.1 & 42.5 & 45.3 & 42.5 & 44.5 \\
\hline $\mathrm{TiO}_{2}$ & 0.95 & 1.03 & 1.01 & 0.88 & 0.92 & 1.01 \\
\hline $\mathrm{Al}_{2} \mathrm{O}_{3}$ & 8.22 & 8.48 & 8.33 & 8.28 & 8.17 & 8.33 \\
\hline $\mathrm{FeO}_{\mathrm{T}}$ & 21.6 & 20.9 & 20.6 & 20.3 & 20.7 & 20.5 \\
\hline $\mathrm{Cr}_{2} \mathrm{O}_{3}$ & 0.49 & 0.48 & 0.49 & 0.45 & 0.30 & 0.46 \\
\hline $\mathrm{MnO}$ & 0.36 & 0.41 & 0.30 & 0.21 & 0.30 & 0.29 \\
\hline $\mathrm{MgO}$ & 8.68 & 8.82 & 8.70 & 9.66 & 8.72 & 8.61 \\
\hline $\mathrm{CaO}$ & 6.62 & 6.55 & 6.38 & 5.90 & 5.79 & 6.05 \\
\hline $\mathrm{Na}_{2} \mathrm{O}$ & 2.60 & 2.34 & 2.46 & 2.78 & 2.67 & 2.39 \\
\hline $\mathrm{K}_{2} \mathrm{O}$ & 0.42 & 0.47 & 0.50 & 0.62 & 0.54 & 0.56 \\
\hline $\mathrm{P}_{2} \mathrm{O}_{5}$ & 0.93 & 0.60 & 1.04 & 1.08 & 1.07 & 0.73 \\
\hline $\mathrm{SO}_{3}$ & 6.42 & 6.22 & 6.23 & 2.59 & 6.62 & 4.96 \\
\hline $\mathrm{Cl}$ & 1.18 & 1.36 & 1.25 & 1.78 & 1.43 & 1.41 \\
\hline CIA & 32.9 & 34.3 & 34.0 & 34.1 & 34.5 & 34.9 \\
\hline $\mathrm{CaO} / \mathrm{Al}_{2} \mathrm{O}_{3}$ & 0.81 & 0.77 & 0.77 & 0.71 & 0.71 & 0.73 \\
\hline $\mathrm{SiO}_{2} / \mathrm{Al}_{2} \mathrm{O}_{3}$ & 5.03 & 4.97 & 5.10 & 5.47 & 5.21 & 5.34 \\
\hline $\mathrm{Al}_{2} \mathrm{O}_{3} / \mathrm{TiO}_{2}$ & 8.65 & 8.23 & 8.25 & 9.41 & 8.88 & 8.25 \\
\hline $\mathrm{FeO}_{\mathrm{T}} / \mathrm{MgO}$ & 2.49 & 2.37 & 2.37 & 2.10 & 2.38 & 2.38 \\
\hline $\mathrm{FeO}_{\mathrm{T}} / \mathrm{MnO}$ & 60.0 & 50.9 & 67.7 & 96.6 & 69.0 & 70.8 \\
\hline $\mathrm{K}{ }_{2} \mathrm{O} / \mathrm{Al}_{2} \mathrm{O}_{3}$ & 0.051 & 0.055 & 0.060 & 0.075 & 0.066 & 0.067 \\
\hline $\mathrm{K}_{2} \mathrm{O} / \mathrm{Na}_{2} \mathrm{O}$ & 0.16 & 0.20 & 0.20 & 0.22 & 0.20 & 0.23 \\
\hline $\mathrm{Cr}$ & 3335 & 3253 & 3341 & 3051 & 2086 & 3149 \\
\hline $\mathrm{Ni}$ & 446 & 494 & 503 & 482 & 569 & 561 \\
\hline $\mathrm{Zn}$ & 794 & 815 & 803 & 789 & 772 & 754 \\
\hline $\mathrm{Ge}$ & 76 & 67 & 81 & 85 & 88 & 59 \\
\hline $\mathrm{Br}$ & 323 & 165 & 308 & 327 & 107 & 218 \\
\hline $\mathrm{Cr} / \mathrm{Ni}$ & 7.48 & 6.59 & 6.64 & 6.33 & 3.67 & 5.61 \\
\hline $\mathrm{Cr} / \mathrm{Zn}$ & 4.20 & 3.99 & 4.16 & 3.87 & 2.70 & 4.18 \\
\hline $\mathrm{Zn} / \mathrm{Ni}$ & 1.78 & 1.65 & 1.60 & 1.64 & 1.36 & 1.34 \\
\hline $\mathrm{S} / \mathrm{Cl}$ & 2.18 & 1.83 & 2.00 & 0.58 & 1.85 & 1.41 \\
\hline $\mathrm{Cl} / \mathrm{Br}$ & 36.5 & 82.4 & 40.6 & 54.4 & 133.6 & 64.7 \\
\hline $\begin{array}{l}\text { Selwyn } \\
\text { Section }\end{array}$ & No & No & Yes & Yes & Yes & Yes \\
\hline Analysis & As is & As is & As is & Brush & As is & As is \\
\hline Sol & 129 & 129 & 150 & 150 & 162 & 161 \\
\hline
\end{tabular}


Table S2.

APXS analyses of the upper part of the Sheepbed member listed in approximate stratigraphic order from the base (major elements in wt \%, trace elements in ppm).

\begin{tabular}{|c|c|c|c|c|c|c|c|}
\hline & $\begin{array}{l}\text { Bonnet } \\
\text { Plume }\end{array}$ & Sayunei_C & Divot2 & $\begin{array}{c}\text { Werneke } \\
\text { Brush }\end{array}$ & $\begin{array}{c}\text { McGrath } \\
\text { R3 }\end{array}$ & $\begin{array}{c}\text { DrillHole } \\
\text { R4 }\end{array}$ & Drill_RP \\
\hline $\mathrm{SiO}_{2}$ & 44.6 & 43.9 & 43.6 & 46.9 & 43.2 & 42.1 & 41.4 \\
\hline $\mathrm{TiO}_{2}$ & 0.81 & 0.87 & 0.94 & 0.91 & 0.90 & 0.99 & 1.05 \\
\hline $\mathrm{Al}_{2} \mathrm{O}_{3}$ & 8.44 & 9.43 & 8.71 & 8.88 & 8.56 & 8.57 & 8.22 \\
\hline $\mathrm{FeO}_{\mathrm{T}}$ & 20.0 & 18.6 & 20.6 & 20.5 & 19.5 & 20.1 & 20.3 \\
\hline $\mathrm{Cr}_{2} \mathrm{O}_{3}$ & 0.43 & 0.47 & 0.42 & 0.41 & 0.43 & 0.40 & 0.35 \\
\hline $\mathrm{MnO}$ & 0.24 & 0.35 & 0.29 & 0.28 & 0.28 & 0.29 & 0.30 \\
\hline $\mathrm{MgO}$ & 8.90 & 8.81 & 9.89 & 9.80 & 8.56 & 9.03 & 8.33 \\
\hline $\mathrm{CaO}$ & 5.83 & 6.01 & 6.16 & 5.40 & 6.63 & 7.73 & 6.89 \\
\hline $\mathrm{Na}_{2} \mathrm{O}$ & 2.47 & 2.89 & 2.98 & 3.04 & 2.61 & 3.00 & 2.48 \\
\hline $\mathrm{K}_{2} \mathrm{O}$ & 0.55 & 0.76 & 0.59 & 0.62 & 0.50 & 0.60 & 0.59 \\
\hline $\mathrm{P}_{2} \mathrm{O}_{5}$ & 0.95 & 1.02 & 0.96 & 1.02 & 0.90 & 0.90 & 0.84 \\
\hline $\mathrm{SO}_{3}$ & 4.82 & 5.16 & 3.55 & 0.89 & 6.24 & 5.52 & 7.81 \\
\hline $\mathrm{Cl}$ & 1.71 & 1.32 & 0.91 & 1.13 & 1.20 & 0.56 & 1.25 \\
\hline CIA & 35.6 & 36.4 & 34.2 & 36.4 & 33.6 & 30.4 & 32.3 \\
\hline $\mathrm{CaO} / \mathrm{Al}_{2} \mathrm{O}_{3}$ & 0.69 & 0.64 & 0.71 & 0.61 & 0.77 & 0.90 & 0.84 \\
\hline $\mathrm{SiO}_{2} / \mathrm{Al}_{2} \mathrm{O}_{3}$ & 5.28 & 4.66 & 5.01 & 5.28 & 5.04 & 4.91 & 5.03 \\
\hline $\mathrm{Al}_{2} \mathrm{O}_{3} / \mathrm{TiO}_{2}$ & 10.42 & 10.84 & 9.27 & 9.76 & 9.51 & 8.66 & 7.83 \\
\hline $\mathrm{FeO}_{\mathrm{T}} / \mathrm{MgO}$ & 2.25 & 2.11 & 2.08 & 2.09 & 2.28 & 2.23 & 2.43 \\
\hline $\mathrm{FeO}_{\mathrm{T}} / \mathrm{MnO}$ & 83.5 & 53.2 & 71.1 & 73.2 & 69.6 & 69.3 & 67.5 \\
\hline $\mathrm{K}_{2} \mathrm{O} / \mathrm{Al}_{2} \mathrm{O}_{3}$ & 0.065 & 0.081 & 0.068 & 0.070 & 0.058 & 0.070 & 0.072 \\
\hline $\mathrm{K}_{2} \mathrm{O} / \mathrm{Na}_{2} \mathrm{O}$ & 0.22 & 0.26 & 0.20 & 0.20 & 0.19 & 0.20 & 0.24 \\
\hline $\mathrm{Cr}$ & 2910 & 3203 & 2842 & 2835 & 2972 & 2730 & 2363 \\
\hline $\mathrm{Ni}$ & 896 & 580 & 711 & 694 & 710 & 621 & 649 \\
\hline $\mathrm{Zn}$ & 862 & 770 & 819 & 794 & 777 & 755 & 814 \\
\hline $\mathrm{Ge}$ & 42 & 47 & 90 & 99 & 55 & 69 & 79 \\
\hline $\mathrm{Br}$ & 211 & 172 & 390 & 401 & 399 & 167 & 544 \\
\hline $\mathrm{Cr} / \mathrm{Ni}$ & 3.25 & 5.52 & 4.00 & 4.09 & 4.19 & 4.40 & 3.64 \\
\hline $\mathrm{Cr} / \mathrm{Zn}$ & 3.38 & 4.16 & 3.47 & 3.57 & 3.82 & 3.62 & 2.90 \\
\hline $\mathrm{Zn} / \mathrm{Ni}$ & 0.96 & 1.33 & 1.15 & 1.14 & 1.09 & 1.22 & 1.25 \\
\hline $\mathrm{S} / \mathrm{Cl}$ & 1.13 & 1.57 & 1.56 & 0.32 & 2.08 & 3.95 & 2.50 \\
\hline $\mathrm{Cl} / \mathrm{Br}$ & 81.0 & 76.7 & 23.3 & 28.2 & 30.1 & 33.5 & 23.0 \\
\hline $\begin{array}{l}\text { Selwyn } \\
\text { Section }\end{array}$ & Yes & No & No & No & No & No & $\mathrm{No}$ \\
\hline Analysis & As is & As is & As is & Brush & As is & Tailings & As is \\
\hline Sol & 161 & 165 & 181 & 169 & 270 & 230 & 168 \\
\hline
\end{tabular}


Table S2 (continued).

\begin{tabular}{|c|c|c|c|c|c|}
\hline & Nastapoka & Brock_Inlier & Persillon & Mavor & $\begin{array}{c}\text { Cumberland } \\
\text { Brush }\end{array}$ \\
\hline $\mathrm{SiO}_{2}$ & 44.6 & 43.6 & 40.4 & 25.9 & 46.8 \\
\hline $\mathrm{TiO}_{2}$ & 0.94 & 0.93 & 0.85 & 0.45 & 0.91 \\
\hline $\mathrm{Al}_{2} \mathrm{O}_{3}$ & 8.77 & 8.41 & 7.90 & 5.13 & 9.33 \\
\hline $\mathrm{FeO}_{\mathrm{T}}$ & 20.4 & 20.1 & 19.1 & 11.9 & 19.8 \\
\hline $\mathrm{Cr}_{2} \mathrm{O}_{3}$ & 0.43 & 0.43 & 0.36 & 0.19 & 0.42 \\
\hline $\mathrm{MnO}$ & 0.20 & 0.29 & 0.22 & 0.19 & 0.27 \\
\hline $\mathrm{MgO}$ & 8.83 & 8.77 & 8.14 & 5.87 & 9.15 \\
\hline $\mathrm{CaO}$ & 5.36 & 6.01 & 7.75 & 18.4 & 5.44 \\
\hline $\mathrm{Na}_{2} \mathrm{O}$ & 2.64 & 2.49 & 2.47 & 1.92 & 3.14 \\
\hline $\mathrm{K}_{2} \mathrm{O}$ & 0.61 & 0.54 & 0.53 & 0.25 & 0.66 \\
\hline $\mathrm{P}_{2} \mathrm{O}_{5}$ & 1.12 & 1.06 & 0.99 & 0.72 & 0.92 \\
\hline $\mathrm{SO}_{3}$ & 4.00 & 5.97 & 9.71 & 28.0 & 1.57 \\
\hline $\mathrm{Cl}$ & 1.93 & 1.19 & 1.44 & 0.97 & 1.33 \\
\hline CIA & 37.3 & 35.0 & 29.7 & 12.2 & 37.2 \\
\hline $\mathrm{CaO} / \mathrm{Al}_{2} \mathrm{O}_{3}$ & 0.61 & 0.71 & 0.98 & 3.59 & 0.58 \\
\hline $\mathrm{SiO}_{2} / \mathrm{Al}_{2} \mathrm{O}_{3}$ & 5.08 & 5.18 & 5.11 & 5.06 & 5.02 \\
\hline $\mathrm{Al}_{2} \mathrm{O}_{3} / \mathrm{TiO}_{2}$ & 9.33 & 9.04 & 9.29 & 11.40 & 10.25 \\
\hline $\mathrm{FeO}_{\mathrm{T}} / \mathrm{MgO}$ & 2.31 & 2.29 & 2.34 & 2.02 & 2.17 \\
\hline $\mathrm{FeO}_{\mathrm{T}} / \mathrm{MnO}$ & 101.9 & 69.2 & 86.7 & 62.4 & 73.4 \\
\hline $\mathrm{K}_{2} \mathrm{O} / \mathrm{Al}_{2} \mathrm{O}_{3}$ & 0.070 & 0.061 & 0.067 & 0.049 & 0.071 \\
\hline $\mathrm{K}_{2} \mathrm{O} / \mathrm{Na}_{2} \mathrm{O}$ & 0.23 & 0.22 & 0.21 & 0.13 & 0.21 \\
\hline $\mathrm{Cr}$ & 2951 & 2924 & 2472 & 1267 & 2893 \\
\hline $\mathrm{Ni}$ & 668 & 855 & 773 & 282 & 698 \\
\hline $\mathrm{Zn}$ & 753 & 843 & 621 & 306 & 776 \\
\hline $\mathrm{Ge}$ & 78 & 99 & 73 & 49 & 90 \\
\hline $\mathrm{Br}$ & 197 & 444 & 100 & 137 & 122 \\
\hline $\mathrm{Cr} / \mathrm{Ni}$ & 4.42 & 3.42 & 3.20 & 4.49 & 4.14 \\
\hline $\mathrm{Cr} / \mathrm{Zn}$ & 3.92 & 3.47 & 3.98 & 4.14 & 3.73 \\
\hline $\mathrm{Zn} / \mathrm{Ni}$ & 1.13 & 0.99 & 0.80 & 1.09 & 1.11 \\
\hline $\mathrm{S} / \mathrm{Cl}$ & 0.83 & 2.01 & 2.70 & 11.6 & 0.47 \\
\hline $\mathrm{Cl} / \mathrm{Br}$ & 98.0 & 26.8 & 144.0 & 70.8 & 109.0 \\
\hline $\begin{array}{l}\text { Selwyn } \\
\text { Section }\end{array}$ & Yes & No & Yes & Yes & No \\
\hline Analysis & As is & As is & As is & Vein-rich & Brush \\
\hline Sol & 158 & 169 & 154 & 158 & 291 \\
\hline
\end{tabular}


Table S3.

APXS analyses of the Gillespie Lake and Glenelg members listed in approximate stratigraphic order from the base (major elements in wt \%, trace elements in ppm).

\begin{tabular}{|c|c|c|c|c|c|c|c|c|c|}
\hline & $\begin{array}{c}\text { Gillespie } \\
\text { Lake mem. }\end{array}$ & \multicolumn{8}{|c|}{ Glenelg member } \\
\hline & Gillespie & $\begin{array}{c}\text { Bell } \\
\text { Island_9 }\end{array}$ & $\begin{array}{c}\text { Dismal } \\
\text { Lake }\end{array}$ & $\begin{array}{c}\text { Rocknest } \\
3^{*}\end{array}$ & Howells & $\begin{array}{c}\text { Aillik_ } \\
\text { RP }\end{array}$ & Eqalulik & $\begin{array}{c}\text { Bathurst } \\
1 *\end{array}$ & $\begin{array}{c}\text { Bathurst } \\
2 *\end{array}$ \\
\hline $\mathrm{SiO}_{2}$ & 45.6 & 42.9 & 49.0 & 46.0 & 44.6 & 42.2 & 42.0 & 43.7 & 43.9 \\
\hline $\mathrm{TiO}_{2}$ & 1.12 & 0.83 & 0.77 & 0.96 & 0.89 & 0.75 & 0.87 & 1.11 & 1.04 \\
\hline $\mathrm{Al}_{2} \mathrm{O}_{3}$ & 9.11 & 9.03 & 11.6 & 10.5 & 9.62 & 8.44 & 8.75 & 7.90 & 8.03 \\
\hline $\mathrm{FeO}_{\mathrm{T}}$ & 19.6 & 18.0 & 14.7 & 18.4 & 18.5 & 20.6 & 20.7 & 21.9 & 20.8 \\
\hline $\mathrm{Cr}_{2} \mathrm{O}_{3}$ & 0.52 & 0.48 & 0.37 & 0.25 & 0.59 & 0.76 & 0.66 & 0.41 & 0.35 \\
\hline $\mathrm{MnO}$ & 0.32 & 0.46 & 0.30 & 0.45 & 0.37 & 0.36 & 0.35 & 0.78 & 0.43 \\
\hline $\mathrm{MgO}$ & 9.18 & 8.17 & 6.30 & 5.33 & 7.72 & 8.71 & 8.24 & 8.60 & 8.78 \\
\hline $\mathrm{CaO}$ & 6.45 & 6.81 & 6.23 & 6.06 & 6.48 & 7.03 & 6.53 & 6.30 & 6.43 \\
\hline $\mathrm{Na}_{2} \mathrm{O}$ & 2.58 & 2.98 & 4.36 & 4.02 & 3.22 & 2.86 & 2.95 & 2.24 & 2.14 \\
\hline $\mathrm{K}_{2} \mathrm{O}$ & 0.51 & 1.02 & 1.64 & 1.86 & 1.20 & 0.46 & 0.79 & 2.18 & 2.88 \\
\hline $\mathrm{P}_{2} \mathrm{O}_{5}$ & 0.88 & 0.96 & 0.9 & 1.08 & 0.76 & 0.73 & 0.8 & 0.83 & 0.89 \\
\hline $\mathrm{SO}_{3}$ & 2.88 & 7.07 & 2.67 & 4.05 & 5.06 & 5.82 & 6.06 & 3.08 & 3.30 \\
\hline $\mathrm{Cl}$ & 1.10 & 1.18 & 0.93 & 0.88 & 0.82 & 1.12 & 1.15 & 0.74 & 0.81 \\
\hline CIA & 35.5 & 32.9 & 36.5 & 34.9 & 34.4 & 31.9 & 33.2 & 31.1 & 30.5 \\
\hline $\mathrm{CaO} / \mathrm{Al}_{2} \mathrm{O}_{3}$ & 0.71 & 0.75 & 0.54 & 0.58 & 0.67 & 0.83 & 0.75 & 0.80 & 0.80 \\
\hline $\mathrm{SiO}_{2} / \mathrm{Al}_{2} \mathrm{O}_{3}$ & 5.01 & 4.75 & 4.21 & 4.37 & 4.64 & 5.00 & 4.80 & 5.53 & 5.47 \\
\hline $\mathrm{Al}_{2} \mathrm{O}_{3} / \mathrm{TiO}_{2}$ & 8.13 & 10.88 & 15.10 & 10.95 & 10.81 & 11.25 & 10.06 & 7.12 & 7.72 \\
\hline $\mathrm{FeO}_{\mathrm{T}} / \mathrm{MgO}$ & 2.14 & 2.20 & 2.33 & 3.45 & 2.40 & 2.36 & 2.51 & 2.55 & 2.37 \\
\hline $\mathrm{FeO}_{\mathrm{T}} / \mathrm{MnO}$ & 61.3 & 39.1 & 49.0 & 40.8 & 50.0 & 57.2 & 59.1 & 28.1 & 48.4 \\
\hline $\mathrm{K}_{2} \mathrm{O} / \mathrm{Al}_{2} \mathrm{O}_{3}$ & 0.056 & 0.113 & 0.141 & 0.177 & 0.125 & 0.055 & 0.090 & 0.276 & 0.359 \\
\hline $\mathrm{K}_{2} \mathrm{O} / \mathrm{Na}_{2} \mathrm{O}$ & 0.20 & 0.34 & 0.38 & 0.46 & 0.37 & 0.16 & 0.27 & 0.97 & 1.35 \\
\hline $\mathrm{Cr}$ & 3545 & 3319 & 2525 & 1686 & 4060 & 5200 & 4487 & 2775 & 2403 \\
\hline $\mathrm{Ni}$ & 320 & 290 & 212 & 364 & 280 & 234 & 279 & 395 & 321 \\
\hline $\mathrm{Zn}$ & 591 & 631 & 480 & 888 & 814 & 984 & 967 & 1332 & 1210 \\
\hline $\mathrm{Ge}$ & 39 & 30 & 31 & 102 & 60 & 51 & 54 & 81 & 46 \\
\hline $\mathrm{Br}$ & 93 & 89 & 104 & 62 & 47 & 408 & 169 & 14 & 39 \\
\hline $\mathrm{Cr} / \mathrm{Ni}$ & 11.08 & 11.44 & 11.91 & 4.63 & 14.50 & 22.22 & 16.08 & 7.03 & 7.49 \\
\hline $\mathrm{Cr} / \mathrm{Zn}$ & 6.00 & 5.26 & 5.26 & 1.90 & 4.99 & 5.28 & 4.64 & 2.08 & 1.99 \\
\hline $\mathrm{Zn} / \mathrm{Ni}$ & 1.85 & 2.18 & 2.26 & 2.44 & 2.91 & 4.21 & 3.47 & 3.37 & 3.77 \\
\hline $\mathrm{S} / \mathrm{Cl}$ & 1.05 & 2.40 & 1.15 & 1.84 & 2.47 & 2.08 & 2.11 & 1.67 & 1.63 \\
\hline $\mathrm{Cl} / \mathrm{Br}$ & 118.3 & 132.6 & 89.4 & 141.9 & 174.5 & 27.5 & 68.0 & 528.6 & 207.7 \\
\hline $\begin{array}{l}\text { Selwyn } \\
\text { Section }\end{array}$ & No & No & No & No & No & No & No & No & $\mathrm{No}$ \\
\hline Analysis & As is & As is & As is & As is & As is & As is & As is & As is & As is \\
\hline Sol & 132 & 117 & 305 & 102 & 323 & 322 & 323 & 54 & 54 \\
\hline
\end{tabular}

*- Rocknest3, Bathurst1 and Bathurst2 from ref. 28. 
Table S4.

APXS analyses of diagenetic features (major elements in wt \%, trace elements in ppm).

\begin{tabular}{|c|c|c|c|c|c|c|c|c|c|c|c|}
\hline & \multirow{2}{*}{$\begin{array}{l}\text { Dike } \\
\begin{array}{l}\text { Snake } \\
\text { River }\end{array} \\
\end{array}$} & \multicolumn{5}{|c|}{ Sayunei Raster Analysis } & \multicolumn{5}{|c|}{ McGrath Raster Analysis } \\
\hline & & Center & $\mathbf{A}$ & B & $\mathbf{C}$ & $\mathbf{D}$ & $\mathbf{R} 1$ & $\mathbf{R 2}$ & $\mathbf{R 2}$ & R4 & R5 \\
\hline $\mathrm{SiO}_{2}$ & 42.3 & 38.4 & 36.9 & 37.5 & 43.9 & 41.9 & 43.2 & 43.7 & 43.2 & 42.7 & 42.6 \\
\hline $\mathrm{TiO}_{2}$ & 1.00 & 0.83 & 0.68 & 0.87 & 0.87 & 0.85 & 1.02 & 0.85 & 0.90 & 0.94 & 0.87 \\
\hline $\mathrm{Al}_{2} \mathrm{O}_{3}$ & 7.52 & 7.45 & 7.44 & 7.78 & 9.43 & 7.77 & 8.35 & 6.70 & 8.56 & 8.16 & 7.24 \\
\hline $\mathrm{FeO}_{\mathrm{T}}$ & 21.7 & 17.7 & 17.1 & 17.4 & 18.6 & 21.7 & 20.5 & 23.6 & 19.5 & 20.2 & 22.6 \\
\hline $\mathrm{Cr}_{2} \mathrm{O}_{3}$ & 0.76 & 0.38 & 0.34 & 0.42 & 0.47 & 0.26 & 0.33 & 0.34 & 0.43 & 0.42 & 0.37 \\
\hline $\mathrm{MnO}$ & 0.34 & 0.24 & 0.23 & 0.27 & 0.35 & 0.32 & 0.26 & 0.35 & 0.28 & 0.28 & 0.33 \\
\hline $\mathrm{MgO}$ & 8.88 & 8.04 & 9.04 & 8.61 & 8.81 & 9.78 & 8.45 & 10.36 & 8.56 & 8.89 & 9.91 \\
\hline $\mathrm{CaO}$ & 6.91 & 9.51 & 9.39 & 9.11 & 6.01 & 5.19 & 5.98 & 4.35 & 6.63 & 6.39 & 5.00 \\
\hline $\mathrm{Na}_{2} \mathrm{O}$ & 2.00 & 2.31 & 2.41 & 2.55 & 2.89 & 2.47 & 2.34 & 2.04 & 2.61 & 2.54 & 2.30 \\
\hline $\mathrm{K}_{2} \mathrm{O}$ & 0.42 & 0.35 & 0.43 & 0.49 & 0.76 & 0.43 & 0.60 & 0.30 & 0.50 & 0.43 & 0.36 \\
\hline $\mathrm{P}_{2} \mathrm{O}_{5}$ & 0.79 & 0.89 & 0.94 & 0.84 & 1.02 & 0.96 & 0.73 & 0.66 & 0.90 & 0.96 & 0.86 \\
\hline $\mathrm{SO}_{3}$ & 5.58 & 12.5 & 13.5 & 12.5 & 5.16 & 6.60 & 6.79 & 4.93 & 6.24 & 6.56 & 5.83 \\
\hline $\mathrm{Cl}$ & 1.50 & 1.24 & 1.44 & 1.44 & 1.32 & 1.60 & 1.18 & 1.60 & 1.20 & 1.28 & 1.49 \\
\hline CIA & 31.6 & 25.8 & 25.7 & 26.8 & 36.4 & 35.7 & 35.2 & 36.6 & 33.6 & 33.4 & 35.3 \\
\hline $\mathrm{CaO} / \mathrm{Al}_{2} \mathrm{O}_{3}$ & 0.92 & 1.28 & 1.26 & 1.17 & 0.64 & 0.67 & 0.72 & 0.65 & 0.77 & 0.78 & 0.69 \\
\hline $\mathrm{SiO}_{2} / \mathrm{Al}_{2} \mathrm{O}_{3}$ & 5.63 & 5.16 & 4.96 & 4.82 & 4.66 & 5.39 & 5.18 & 6.52 & 5.04 & 5.23 & 5.88 \\
\hline $\mathrm{Al}_{2} \mathrm{O}_{3} / \mathrm{TiO}_{2}$ & 7.52 & 8.98 & 10.94 & 8.94 & 10.84 & 9.14 & 8.19 & 7.88 & 9.51 & 8.68 & 8.32 \\
\hline $\mathrm{FeO}_{\mathrm{T}} / \mathrm{MgO}$ & 2.44 & 2.20 & 1.89 & 2.02 & 2.11 & 2.22 & 2.43 & 2.27 & 2.28 & 2.27 & 2.28 \\
\hline $\mathrm{FeO}_{\mathrm{T}} / \mathrm{MnO}$ & 63.7 & 73.6 & 74.4 & 64.4 & 53.2 & 67.8 & 78.9 & 67.3 & 69.6 & 72.1 & 68.6 \\
\hline $\mathrm{K}_{2} \mathrm{O} / \mathrm{Al}_{2} \mathrm{O}_{3}$ & 0.056 & 0.047 & 0.058 & 0.063 & 0.081 & 0.055 & 0.072 & 0.045 & 0.058 & 0.053 & 0.050 \\
\hline $\mathrm{K}_{2} \mathrm{O} / \mathrm{Na}_{2} \mathrm{O}$ & 0.21 & 0.15 & 0.18 & 0.19 & 0.26 & 0.17 & 0.26 & 0.15 & 0.19 & 0.17 & 0.16 \\
\hline $\mathrm{Cr}$ & 5170 & 2617 & 2294 & 2875 & 3203 & 1800 & 2140 & 2311 & 2972 & 2858 & 2550 \\
\hline $\mathrm{Ni}$ & 175 & 618 & 654 & 687 & 580 & 921 & 554 & 712 & 710 & 582 & 745 \\
\hline $\mathrm{Zn}$ & 819 & 602 & 642 & 621 & 770 & 824 & 728 & 893 & 777 & 753 & 815 \\
\hline $\mathrm{Ge}$ & 0 & 84 & 93 & 32 & 47 & 121 & 70 & 101 & 55 & 98 & 122 \\
\hline $\mathrm{Br}$ & 139 & 160 & 193 & 135 & 172 & 164 & 322 & 569 & 399 & 481 & 517 \\
\hline $\mathrm{Cr} / \mathrm{Ni}$ & 29.54 & 4.23 & 3.51 & 4.18 & 5.52 & 1.95 & 3.86 & 3.25 & 4.19 & 4.91 & 3.42 \\
\hline $\mathrm{Cr} / \mathrm{Zn}$ & 6.31 & 4.35 & 3.57 & 4.63 & 4.16 & 2.18 & 2.94 & 2.59 & 3.82 & 3.80 & 3.13 \\
\hline $\mathrm{Zn} / \mathrm{Ni}$ & 4.68 & 0.97 & 0.98 & 0.90 & 1.33 & 0.89 & 1.31 & 1.25 & 1.09 & 1.29 & 1.09 \\
\hline $\mathrm{S} / \mathrm{Cl}$ & 1.49 & 4.04 & 3.75 & 3.47 & 1.57 & 1.65 & 2.30 & 1.23 & 2.08 & 2.05 & 1.57 \\
\hline $\mathrm{Cl} / \mathrm{Br}$ & 107.9 & 77.5 & 74.6 & 106.7 & 76.7 & 97.6 & 36.6 & 28.1 & 30.1 & 26.6 & 28.8 \\
\hline $\begin{array}{l}\text { Selwyn } \\
\text { Section }\end{array}$ & Yes & No & No & No & No & No & No & No & No & No & No \\
\hline Analysis & As is & As is & As is & As is & As is & As is & As is & As is & As is & As is & As is \\
\hline Sol & 149 & 165 & 165 & 165 & 165 & 165 & 270 & 270 & 270 & 270 & 270 \\
\hline
\end{tabular}


Table S5.

John_Klein - Cumberland constant oxide gain-loss calculations.

\begin{tabular}{|c|c|c|c|c|c|c|}
\hline & $\begin{array}{c}\text { John_Klein } \\
\text { Drill Fines }\end{array}$ & Anhydrite & $\begin{array}{c}\text { John_Klein } \\
\text { less 5\% } \\
\text { Anhydrite }\end{array}$ & $\begin{array}{l}\text { Cumberland } \\
\text { Drill Fines }\end{array}$ & $\begin{array}{c}\text { Gain/Loss } \\
\text { for Al } \\
\text { immobile }\end{array}$ & $\begin{array}{c}\text { Gain/Loss } \\
\text { for Ti } \\
\text { immobile }\end{array}$ \\
\hline $\mathrm{SiO}_{2}$ & 41.0 & & 43.2 & 43.0 & 3.7 & 9.9 \\
\hline $\mathrm{TiO}_{2}$ & 1.02 & & 1.07 & 0.97 & -5.6 & 0.0 \\
\hline $\mathrm{Al}_{2} \mathrm{O}_{3}$ & 8.47 & & 8.92 & 8.57 & 0.0 & 6.0 \\
\hline $\mathrm{FeO}_{\mathrm{T}}$ & 20.8 & & 21.9 & 22.4 & 6.4 & 12.8 \\
\hline $\mathrm{Cr}_{2} \mathrm{O}_{3}$ & 0.467 & & 0.49 & 0.432 & -8.5 & -3.1 \\
\hline $\mathrm{MnO}$ & 0.32 & & 0.34 & 0.3 & -7.3 & -1.8 \\
\hline $\mathrm{MgO}$ & 8.92 & & 9.39 & 9.41 & 4.3 & 10.6 \\
\hline $\mathrm{CaO}$ & 7.92 & 41.20 & 6.17 & 6.29 & 6.1 & 12.5 \\
\hline $\mathrm{Na}_{2} \mathrm{O}$ & 2.95 & & 3.11 & 2.98 & -0.1 & 5.9 \\
\hline $\mathrm{K}_{2} \mathrm{O}$ & 0.54 & & 0.57 & 0.5 & -8.4 & -3.0 \\
\hline $\mathrm{P}_{2} \mathrm{O}_{5}$ & 0.91 & & 0.96 & 0.95 & 3.2 & 9.4 \\
\hline $\mathrm{SO}_{3}$ & 5.94 & 58.80 & 3.16 & 2.57 & -15.3 & -10.2 \\
\hline $\mathrm{Cl}$ & 0.53 & & 0.56 & 1.41 & 163.1 & 178.8 \\
\hline $\mathrm{Ni}$ & 698 & & 734.7 & 882 & 24.9 & 32.4 \\
\hline $\mathrm{Zn}$ & 810 & & 852.6 & 856 & 4.5 & 10.7 \\
\hline $\mathrm{Ge}$ & 77 & & 81.1 & 95 & 22.0 & 29.3 \\
\hline $\mathrm{Br}$ & 45 & & 47.4 & 115 & 152.7 & 167.8 \\
\hline
\end{tabular}


Table S6.

Mass balance calculations estimating the composition of a Mg-rich component in raised ridges, identified by ChemCam, using analyses from McGrath APXS raster analysis.

\begin{tabular}{|l|r|r|r|r|r|r|}
\hline & $\begin{array}{c}\text { McGrath } \\
\text { R1 }\end{array}$ & $\begin{array}{c}\text { McGrath } \\
\text { R2 }\end{array}$ & $\begin{array}{c}\text { 10\% } \\
\text { Component }\end{array}$ & $\begin{array}{c}\text { 15\% } \\
\text { Component }\end{array}$ & $\begin{array}{c}\text { 20\% } \\
\text { Component }\end{array}$ & $\begin{array}{c}\text { 25\% } \\
\text { Component }\end{array}$ \\
\hline $\mathrm{SiO}_{2}$ & 43.2 & 43.7 & 48.0 & 46.4 & 45.6 & 45.2 \\
\hline $\mathrm{TiO}_{2}$ & 1.02 & 0.85 & $\mathbf{- 0 . 6 8}$ & $\mathbf{- 0 . 1 1}$ & 0.17 & 0.34 \\
\hline $\mathrm{Al}_{2} \mathrm{O}_{3}$ & 8.35 & 6.7 & $\mathbf{- 8 . 1 5}$ & $\mathbf{- 2 . 6 5}$ & 0.10 & 1.75 \\
\hline $\mathrm{FeO}_{\mathrm{T}}$ & 20.5 & 23.6 & 50.8 & 40.7 & 35.7 & 32.6 \\
\hline $\mathrm{Cr}_{2} \mathrm{O}_{3}$ & 0.33 & 0.34 & 0.43 & 0.40 & 0.38 & 0.37 \\
\hline $\mathrm{MnO}$ & 0.26 & 0.35 & 1.16 & 0.86 & 0.71 & 0.62 \\
\hline $\mathrm{MgO}$ & 8.45 & 10.36 & 27.55 & 21.18 & 18.00 & 16.09 \\
\hline $\mathrm{CaO}$ & 5.98 & 4.35 & -10.32 & -4.89 & -2.17 & -0.54 \\
\hline $\mathrm{Na}_{2} \mathrm{O}$ & 2.34 & 2.04 & $-\mathbf{0 . 6 6}$ & 0.34 & 0.84 & 1.14 \\
\hline $\mathrm{K}_{2} \mathrm{O}$ & 0.596 & 0.297 & -2.39 & -1.40 & -0.90 & -0.60 \\
\hline $\mathrm{P}_{2} \mathrm{O}_{5}$ & 0.73 & 0.66 & 0.03 & 0.26 & 0.38 & 0.45 \\
\hline $\mathrm{SO} \mathrm{S}_{3}$ & 6.79 & 4.93 & -11.81 & -5.61 & -2.51 & -0.65 \\
\hline $\mathrm{Cl}$ & 1.18 & 1.6 & 5.38 & 3.98 & 3.28 & 2.86 \\
\hline $\mathrm{Ni}$ & 554 & 712 & 2134 & 1607 & 1344 & 1186 \\
\hline $\mathrm{Zn}$ & 728 & 893 & 2378 & 1828 & 1553 & 1388 \\
\hline $\mathrm{Ge}$ & 70 & 101 & 380 & 277 & 225 & 194 \\
\hline $\mathrm{Br}$ & 322 & 569 & 2792 & 1969 & 1557 & 1310 \\
\hline
\end{tabular}


Table S7.

Statistical errors (precision) for reported APXS analyses.

\begin{tabular}{|c|c|c|c|c|c|c|c|c|c|c|c|c|c|c|c|c|c|}
\hline Sol & Sample & $\mathrm{Na}_{2} \mathrm{O}$ & MgO & $\mathrm{Al}_{2} \mathrm{O}_{3}$ & $\mathrm{SiO}_{2}$ & $\mathbf{P}_{2} \mathbf{O}_{5}$ & $\mathrm{SO}_{3}$ & $\mathrm{Cl}$ & $\mathrm{K}_{2} \mathrm{O}$ & $\mathrm{CaO}$ & $\mathrm{TiO}_{2}$ & $\mathrm{Cr}_{2} \mathrm{O}_{3}$ & MnO & $\mathrm{FeO}$ & $\mathbf{N i}$ & Zn & $\mathrm{Br}$ \\
\hline 54 & Bathurst1 & 0.27 & 0.33 & 0.37 & 0.58 & 0.07 & 0.11 & 0.03 & 0.04 & 0.08 & 0.04 & 0.03 & 0.03 & 0.15 & 38 & 38 & 8 \\
\hline 54 & Bathurst2 & 0.31 & 0.35 & 0.38 & 0.57 & 0.08 & 0.11 & 0.03 & 0.05 & 0.08 & 0.04 & 0.03 & 0.02 & 0.13 & 32 & 32 & 10 \\
\hline 102 & $\begin{array}{l}\text { Rocknest3 } \\
\text { rock }\end{array}$ & 0.45 & 0.52 & 0.58 & 0.77 & 0.15 & 0.16 & 0.04 & 0.05 & 0.09 & 0.04 & 0.03 & 0.03 & 0.13 & 37 & 30 & 10 \\
\hline 117 & BellIsland & 0.14 & 0.17 & 0.16 & 0.57 & 0.05 & 0.16 & 0.04 & 0.03 & 0.09 & 0.05 & 0.03 & 0.02 & 0.15 & 33 & 28 & 8 \\
\hline 129 & Costello & 0.58 & 0.59 & 0.71 & 1.03 & 0.32 & 0.25 & 0.06 & 0.03 & 0.09 & 0.09 & 0.03 & 0.03 & 0.11 & 35 & 24 & 9 \\
\hline 129 & Flaherty & 0.05 & 0.09 & 0.09 & 0.32 & 0.02 & 0.06 & 0.01 & 0.01 & 0.04 & 0.01 & 0.01 & 0.01 & 0.09 & 11 & 10 & 4 \\
\hline 132 & Gillespie & 0.32 & 0.38 & 0.43 & 0.63 & 0.09 & 0.11 & 0.04 & 0.02 & 0.07 & 0.04 & 0.03 & 0.02 & 0.12 & 32 & 23 & 8 \\
\hline 149 & $\begin{array}{l}\text { Snake_- } \\
\text { River }\end{array}$ & 0.39 & 0.38 & 0.31 & 0.71 & 0.16 & 0.31 & 0.10 & 0.05 & 0.16 & 0.17 & 0.07 & 0.06 & 0.23 & 87 & 70 & 27 \\
\hline 150 & Grit & 0.16 & 0.20 & 0.18 & 0.59 & 0.06 & 0.17 & 0.05 & 0.02 & 0.10 & 0.05 & 0.03 & 0.02 & 0.18 & 50 & 39 & 16 \\
\hline 150 & $\begin{array}{l}\text { Ekwir1_- } \\
\text { Brush }\end{array}$ & 0.05 & 0.10 & 0.09 & 0.35 & 0.02 & 0.03 & 0.02 & 0.01 & 0.03 & 0.01 & 0.01 & 0.01 & 0.09 & 10 & 9 & 4 \\
\hline 154 & Persillon & 0.06 & 0.09 & 0.09 & 0.34 & 0.02 & 0.10 & 0.02 & 0.01 & 0.05 & 0.01 & 0.01 & 0.01 & 0.09 & 17 & 10 & 3 \\
\hline 158 & Mavor & 0.15 & 0.17 & 0.14 & 0.42 & 0.08 & 0.46 & 0.05 & 0.02 & 0.21 & 0.04 & 0.03 & 0.02 & 0.14 & 43 & 28 & 13 \\
\hline 158 & Nastapoka & 0.05 & 0.09 & 0.09 & 0.35 & 0.02 & 0.05 & 0.02 & 0.01 & 0.03 & 0.02 & 0.01 & 0.01 & 0.09 & 13 & 9 & 4 \\
\hline 161 & $\begin{array}{l}\text { Bonnet_- } \\
\text { Plume }\end{array}$ & 0.23 & 0.25 & 0.22 & 0.61 & 0.08 & 0.19 & 0.07 & 0.03 & 0.11 & 0.05 & 0.04 & 0.03 & 0.18 & 71 & 46 & 16 \\
\hline 161 & HudsonBay & 0.27 & 0.26 & 0.24 & 0.57 & 0.10 & 0.20 & 0.06 & 0.03 & 0.10 & 0.11 & 0.04 & 0.03 & 0.17 & 60 & 41 & 17 \\
\hline 161 & Yukon & 0.07 & 0.10 & 0.12 & 0.41 & 0.02 & 0.09 & 0.02 & 0.01 & 0.05 & 0.02 & 0.01 & 0.01 & 0.09 & 16 & 12 & 4 \\
\hline 162 & HayCreek & 0.18 & 0.22 & 0.21 & 0.64 & 0.07 & 0.20 & 0.06 & 0.03 & 0.10 & 0.07 & 0.03 & 0.03 & 0.20 & 57 & 43 & 13 \\
\hline 165 & Sayunei_A & 0.19 & 0.27 & 0.22 & 0.68 & 0.08 & 0.37 & 0.08 & 0.03 & 0.17 & 0.05 & 0.04 & 0.03 & 0.21 & 74 & 51 & 19 \\
\hline 165 & Sayunei_B & 0.22 & 0.28 & 0.24 & 0.71 & 0.08 & 0.37 & 0.08 & 0.04 & 0.18 & 0.06 & 0.05 & 0.03 & 0.22 & 82 & 54 & 19 \\
\hline 165 & Sayunei_C & 0.25 & 0.32 & 0.29 & 0.91 & 0.10 & 0.26 & 0.09 & 0.05 & 0.16 & 0.11 & 0.06 & 0.04 & 0.25 & 97 & 69 & 23 \\
\hline 165 & Sayunei_D & 0.23 & 0.30 & 0.25 & 0.77 & 0.08 & 0.26 & 0.09 & 0.04 & 0.13 & 0.06 & 0.04 & 0.04 & 0.25 & 95 & 61 & 20 \\
\hline 165 & Sayunei & 0.05 & 0.08 & 0.07 & 0.22 & 0.02 & 0.10 & 0.02 & 0.01 & 0.05 & 0.01 & 0.01 & 0.01 & 0.05 & 15 & 10 & 4 \\
\hline 168 & Drill_RP & 0.33 & 0.33 & 0.35 & 0.61 & 0.12 & 0.25 & 0.06 & 0.03 & 0.11 & 0.05 & 0.04 & 0.03 & 0.17 & 61 & 41 & 21 \\
\hline 169 & BrockInlier & 0.19 & 0.23 & 0.22 & 0.65 & 0.07 & 0.19 & 0.06 & 0.03 & 0.11 & 0.05 & 0.03 & 0.03 & 0.19 & 66 & 43 & 21 \\
\hline 169 & $\begin{array}{l}\text { Wernecke_ } \\
\text { Brushed }\end{array}$ & 0.06 & 0.10 & 0.10 & 0.39 & 0.02 & 0.02 & 0.02 & 0.01 & 0.03 & 0.01 & 0.01 & 0.01 & 0.10 & 15 & 11 & 5 \\
\hline 181 & Divot2 & 0.08 & 0.12 & 0.11 & 0.40 & 0.02 & 0.06 & 0.02 & 0.01 & 0.05 & 0.02 & 0.01 & 0.01 & 0.11 & 22 & 15 & 7 \\
\hline 230 & DrillHoleR4 & 0.26 & 0.28 & 0.28 & 0.69 & 0.08 & 0.21 & 0.05 & 0.04 & 0.14 & 0.06 & 0.04 & 0.03 & 0.21 & 76 & 52 & 26 \\
\hline 270 & $\begin{array}{l}\text { MacGrath } \\
\text { R1 }\end{array}$ & 0.37 & 0.44 & 0.49 & 0.71 & 0.11 & 0.21 & 0.05 & 0.03 & 0.09 & 0.05 & 0.03 & 0.03 & 0.16 & 54 & 37 & 16 \\
\hline 270 & $\begin{array}{l}\text { MacGrath } \\
\text { R2 }\end{array}$ & 0.27 & 0.33 & 0.37 & 0.52 & 0.07 & 0.13 & 0.05 & 0.02 & 0.07 & 0.04 & 0.03 & 0.02 & 0.13 & 49 & 34 & 16 \\
\hline 270 & $\begin{array}{l}\text { MacGrath } \\
\text { R3 }\end{array}$ & 0.24 & 0.29 & 0.33 & 0.56 & 0.07 & 0.17 & 0.05 & 0.02 & 0.09 & 0.05 & 0.03 & 0.02 & 0.16 & 51 & 34 & 18 \\
\hline 270 & $\begin{array}{l}\text { MacGrath } \\
\text { R4 }\end{array}$ & 0.13 & 0.17 & 0.15 & 0.49 & 0.05 & 0.15 & 0.04 & 0.02 & 0.08 & 0.04 & 0.02 & 0.02 & 0.15 & 39 & 29 & 14 \\
\hline 270 & $\begin{array}{l}\text { MacGrath } \\
\text { R5 }\end{array}$ & 0.09 & 0.13 & 0.14 & 0.28 & 0.02 & 0.06 & 0.02 & 0.01 & 0.03 & 0.01 & 0.01 & 0.01 & 0.09 & 17 & 12 & 6 \\
\hline 291 & $\begin{array}{l}\text { Cumberland } \\
\text { Brush }\end{array}$ & 0.06 & 0.10 & 0.10 & 0.38 & 0.02 & 0.03 & 0.02 & 0.01 & 0.03 & 0.01 & 0.01 & 0.01 & 0.09 & 14 & 10 & 4 \\
\hline 305 & DismalLake & 0.08 & 0.08 & 0.12 & 0.38 & 0.02 & 0.04 & 0.02 & 0.02 & 0.04 & 0.01 & 0.01 & 0.01 & 0.08 & 12 & 10 & 3 \\
\hline 322 & $\begin{array}{l}\text { Aillik_RP_- } \\
\text { overnight }\end{array}$ & 0.06 & 0.09 & 0.09 & 0.34 & 0.02 & 0.06 & 0.02 & 0.01 & 0.04 & 0.01 & 0.01 & 0.01 & 0.09 & 10 & 12 & 5 \\
\hline 323 & Howells & 0.13 & 0.16 & 0.17 & 0.57 & 0.04 & 0.13 & 0.03 & 0.03 & 0.08 & 0.03 & 0.03 & 0.02 & 0.15 & 31 & 30 & 7 \\
\hline 323 & Eqalulik & 0.06 & 0.09 & 0.09 & 0.33 & 0.01 & 0.06 & 0.01 & 0.01 & 0.04 & 0.01 & 0.01 & 0.01 & 0.09 & 9 & 10 & 3 \\
\hline
\end{tabular}


Table S8.

ChemCam PLS1 algorithm and training set details.

\begin{tabular}{|c|c|c|c|c|c|c|c|c|}
\hline & $\mathrm{SiO}_{2}$ & $\mathrm{TiO}_{2}$ & $\mathrm{Al}_{2} \mathrm{O}_{3}$ & $\mathrm{FeO}_{\mathrm{T}}$ & MgO & $\mathrm{CaO}$ & $\mathrm{Na}_{2} \mathbf{O}$ & $\mathbf{K}_{2} \mathbf{O}$ \\
\hline Training set min. (wt \%) & 0.2 & 0.0 & 0.0 & 0.0 & 0.0 & 0.1 & 0.0 & 0.0 \\
\hline Training set $1^{\text {st }}$ quartile (wt $\%$ ) & 40.8 & 0.27 & 5.0 & 2.7 & 0.8 & 2.5 & 0.30 & 0.3 \\
\hline Training set median (wt \%) & 48.6 & 0.68 & 13.1 & 6.0 & 2.2 & 7.1 & 2.4 & 0.8 \\
\hline Training set $3^{\text {rd }}$ quartile (wt $\%$ ) & 59.3 & 1.47 & 16.1 & 12.1 & 6.4 & 12.8 & 3.4 & 1.8 \\
\hline Training set max. (wt \%) & 75.4 & 5.9 & 38.8 & 36.2 & 49.2 & 54.9 & 5.9 & 6.4 \\
\hline Normalization (spectral regions) & 3 & 1 & 1 & 1 & 1 & 3 & 1 & 3 \\
\hline Number of principal components & 8 & 10 & 4 & 7 & 8 & 8 & 10 & 4 \\
\hline RMS error product (wt \%) & 7.1 & 0.6 & 3.7 & 4.0 & 3.0 & 3.3 & 0.7 & 0.9 \\
\hline
\end{tabular}


Mars Science Laboratory (MSL) Science Team

Aalto University

Osku Kemppinen

Applied Physics Laboratory (APL) at Johns Hopkins University

Nathan Bridges, Jeffrey R. Johnson, Michelle Minitti

Applied Research Associates, Inc. (ARA)

David Cremers

Arizona State University (ASU)

James F. Bell III, Lauren Edgar, Jack Farmer, Austin Godber, Meenakshi Wadhwa,

Danika Wellington

Ashima Research

Ian McEwan, Claire Newman, Mark Richardson

\title{
ATOS Origin
}

Antoine Charpentier, Laurent Peret

\author{
Australian National University (ANU) \\ Penelope King
}

Bay Area Environmental Research Institute (BAER)

Jennifer Blank

\section{Big Head Endian LLC}

Gerald Weigle

\section{Brock University}

Mariek Schmidt

Brown University

Shuai Li, Ralph Milliken, Kevin Robertson, Vivian Sun

California Institute of Technology (Caltech)

Michael Baker, Christopher Edwards, Bethany Ehlmann, Kenneth Farley, Jennifer

Griffes, John Grotzinger, Hayden Miller, Megan Newcombe, Cedric Pilorget, Melissa

Rice, Kirsten Siebach, Katie Stack, Edward Stolper

Canadian Space Agency (CSA)

Claude Brunet, Victoria Hipkin, Richard Léveillé, Geneviève Marchand, Pablo Sobrón

Sánchez

\section{Capgemini France \\ Laurent Favot}

Carnegie Institution of Washington

George Cody, Andrew Steele 
Carnegie Mellon University

Lorenzo Flückiger, David Lees, Ara Nefian

Catholic University of America

Mildred Martin

Centre National de la Recherche Scientifique (CNRS)

Marc Gailhanou, Frances Westall, Guy Israël

Centre National d'Etudes Spatiales (CNES)

Christophe Agard, Julien Baroukh, Christophe Donny, Alain Gaboriaud, Philippe

Guillemot, Vivian Lafaille, Eric Lorigny, Alexis Paillet, René Pérez, Muriel Saccoccio,

Charles Yana

Centro de Astrobiología (CAB)

Carlos Armiens-Aparicio, Javier Caride Rodríguez, Isaías Carrasco Blázquez, Felipe Gómez Gómez, Javier Gómez-Elvira, Sebastian Hettrich, Alain Lepinette Malvitte, Mercedes Marín Jiménez, Jesús Martínez-Frías, Javier Martín-Soler, F. Javier MartínTorres, Antonio Molina Jurado, Luis Mora-Sotomayor, Guillermo Muñoz Caro, Sara Navarro López, Verónica Peinado-González, Jorge Pla-García, José Antonio Rodriguez Manfredi, Julio José Romeral-Planelló, Sara Alejandra Sans Fuentes, Eduardo Sebastian Martinez, Josefina Torres Redondo, Roser Urqui-O'Callaghan, María-Paz Zorzano Mier

Chesapeake Energy

Steve Chipera

Commissariat à l'Énergie Atomique et aux Énergies Alternatives (CEA)

Jean-Luc Lacour, Patrick Mauchien, Jean-Baptiste Sirven

Concordia College

Heidi Manning

Cornell University

Alberto Fairén, Alexander Hayes, Jonathan Joseph, Steven Squyres, Robert Sullivan, Peter Thomas

CS Systemes d'Information

Audrey Dupont

Delaware State University

Angela Lundberg, Noureddine Melikechi, Alissa Mezzacappa

Denver Museum of Nature \& Science

Julia DeMarines, David Grinspoon

Deutsches Zentrum für Luft- und Raumfahrt (DLR)

Günther Reitz

eINFORMe Inc. (at NASA GSFC)

Benito Prats

Finnish Meteorological Institute

Evgeny Atlaskin, Maria Genzer, Ari-Matti Harri, Harri Haukka, Henrik Kahanpää, Janne

Kauhanen, Osku Kemppinen, Mark Paton, Jouni Polkko, Walter Schmidt, Tero Siili 


\section{GeoRessources}

Cécile Fabre

Georgia Institute of Technology

James Wray, Mary Beth Wilhelm

Géosciences Environnement Toulouse (GET)

Franck Poitrasson

Global Science \& Technology, Inc.

Kiran Patel

Honeybee Robotics

Stephen Gorevan, Stephen Indyk, Gale Paulsen

Imperial College

Sanjeev Gupta

Indiana University Bloomington

David Bish, Juergen Schieber

Institut d'Astrophysique Spatiale (IAS)

Brigitte Gondet, Yves Langevin

Institut de Chimie des Milieux et Matériaux de Poitiers (IC2MP)

Claude Geffroy

Institut de Recherche en Astrophysique et Planétologie (IRAP), Université de Toulouse

David Baratoux, Gilles Berger, Alain Cros, Claude d'Uston, Olivier Forni, Olivier Gasnault, Jérémie Lasue, Qiu-Mei Lee, Sylvestre Maurice, Pierre-Yves Meslin, Etienne Pallier, Yann Parot, Patrick Pinet, Susanne Schröder, Mike Toplis

Institut des Sciences de la Terre (ISTerre)

Eric Lewin

inXitu

Will Brunner

Jackson State University

Ezat Heydari

Jacobs Technology

Cherie Achilles, Dorothy Oehler, Brad Sutter

Laboratoire Atmosphères, Milieux, Observations Spatiales (LATMOS)

Michel Cabane, David Coscia, Guy Israël, Cyril Szopa

Laboratoire de Géologié de Lyon : Terre, Planète, Environnement (LGL-TPE)

Gilles Dromart

Laboratoire de Minéralogie et Cosmochimie du Muséum (LMCM)

François Robert, Violaine Sautter 
Laboratoire de Planétologie et Géodynamique de Nantes (LPGN)

Stéphane Le Mouélic, Nicolas Mangold, Marion Nachon

Laboratoire Génie des Procédés et Matériaux (LGPM)

Arnaud Buch

Laboratoire Interuniversitaire des Systèmes Atmosphériques (LISA)

Fabien Stalport, Patrice Coll, Pascaline François, François Raulin, Samuel Teinturier

\section{Lightstorm Entertainment Inc.}

James Cameron

\section{Los Alamos National Lab (LANL)}

Sam Clegg, Agnès Cousin, Dorothea DeLapp, Robert Dingler, Ryan Steele Jackson,

Stephen Johnstone, Nina Lanza, Cynthia Little, Tony Nelson, Roger C. Wiens, Richard B. Williams

\section{Lunar and Planetary Institute (LPI)}

Andrea Jones, Laurel Kirkland, Allan Treiman

\section{Malin Space Science Systems (MSSS)}

Burt Baker, Bruce Cantor, Michael Caplinger, Scott Davis, Brian Duston, Kenneth Edgett, Donald Fay, Craig Hardgrove, David Harker, Paul Herrera, Elsa Jensen, Megan R. Kennedy, Gillian Krezoski, Daniel Krysak, Leslie Lipkaman, Michael Malin, Elaina McCartney, Sean McNair, Brian Nixon, Liliya Posiolova, Michael Ravine, Andrew Salamon, Lee Saper, Kevin Stoiber, Kimberley Supulver, Jason Van Beek, Tessa Van Beek, Robert Zimdar

Massachusetts Institute of Technology (MIT)

Katherine Louise French, Karl Iagnemma, Kristen Miller, Roger Summons

Max Planck Institute for Solar System Research

Fred Goesmann, Walter Goetz, Stubbe Hviid

\section{Microtel}

Micah Johnson, Matthew Lefavor, Eric Lyness

Mount Holyoke College

Elly Breves, M. Darby Dyar, Caleb Fassett

\section{NASA Ames}

David F. Blake, Thomas Bristow, David DesMarais, Laurence Edwards, Robert Haberle,

Tori Hoehler, Jeff Hollingsworth, Melinda Kahre, Leslie Keely, Christopher McKay, Mary Beth Wilhelm

\section{NASA Goddard Space Flight Center (GSFC)}

Lora Bleacher, William Brinckerhoff, David Choi, Pamela Conrad, Jason P. Dworkin, Jennifer Eigenbrode, Melissa Floyd, Caroline Freissinet, James Garvin, Daniel Glavin, Daniel Harpold, Andrea Jones, Paul Mahaffy, David K. Martin, Amy McAdam, Alexander Pavlov, Eric Raaen, Michael D. Smith, Jennifer Stern, Florence Tan, Melissa Trainer

NASA Headquarters

Michael Meyer, Arik Posner, Mary Voytek 
NASA Jet Propulsion Laboratory (JPL)

Robert C, Anderson, Andrew Aubrey, Luther W. Beegle, Alberto Behar, Diana Blaney, David Brinza, Fred Calef, Lance Christensen, Joy A. Crisp, Lauren DeFlores, Bethany Ehlmann, Jason Feldman, Sabrina Feldman, Gregory Flesch, Joel Hurowitz, Insoo Jun, Didier Keymeulen, Justin Maki, Michael Mischna, John Michael Morookian, Timothy Parker, Betina Pavri, Marcel Schoppers, Aaron Sengstacken, John J. Simmonds, Nicole Spanovich, Manuel de la Torre Juarez, Ashwin R. Vasavada, Christopher R. Webster, Albert Yen

NASA Johnson Space Center (JSC)

Paul Douglas Archer, Francis Cucinotta, John H. Jones, Douglas Ming, Richard V. Morris, Paul Niles, Elizabeth Rampe

Nolan Engineering

Thomas Nolan

Oregon State University

Martin Fisk

Piezo Energy Technologies

Leon Radziemski

Planetary Science Institute

Bruce Barraclough, Steve Bender, Daniel Berman, Eldar Noe Dobrea, Robert Tokar, David Vaniman, Rebecca M. E. Williams, Aileen Yingst

Princeton University

Kevin Lewis

Rensselaer Polytechnic Institute (RPI)

Laurie Leshin

Retired

Timothy Cleghorn, Wesley Huntress, Gérard Manhès

Salish Kootenai College

Judy Hudgins, Timothy Olson, Noel Stewart

Search for Extraterrestrial Intelligence Institute (SETI I)

Philippe Sarrazin

Smithsonian Institution

John Grant, Edward Vicenzi, Sharon A. Wilson

Southwest Research Institute (SwRI)

Mark Bullock, Bent Ehresmann, Victoria Hamilton, Donald Hassler, Joseph Peterson, Scot Rafkin, Cary Zeitlin

Space Research Institute

Fedor Fedosov, Dmitry Golovin, Natalya Karpushkina, Alexander Kozyrev, Maxim Litvak, Alexey Malakhov, Igor Mitrofanov, Maxim Mokrousov, Sergey Nikiforov, Vasily Prokhorov, Anton Sanin, Vladislav Tretyakov, Alexey Varenikov, Andrey

Vostrukhin, Ruslan Kuzmin 
Space Science Institute (SSI)

Benton Clark, Michael Wolff

State University of New York (SUNY) Stony Brook

Scott McLennan

Swiss Space Office

Oliver Botta

TechSource

Darrell Drake

Texas A\&M

Keri Bean, Mark Lemmon

The Open University

Susanne P. Schwenzer

United States Geological Survey (USGS) Flagstaff

Ryan B. Anderson, Kenneth Herkenhoff, Ella Mae Lee, Robert Sucharski

Universidad de Alcalá

Miguel Ángel de Pablo Hernández, Juan José Blanco Ávalos, Miguel Ramos

Universities Space Research Association (USRA)

Myung-Hee Kim, Charles Malespin, Ianik Plante

University College London (UCL)

Jan-Peter Muller

University Nacional Autónoma de México (UNAM)

Rafael Navarro-González

University of Alabama

Ryan Ewing

University of Arizona

William Boynton, Robert Downs, Mike Fitzgibbon, Karl Harshman, Shaunna Morrison

University of California Berkeley

William Dietrich, Onno Kortmann, Marisa Palucis

University of California Davis

Dawn Y. Sumner, Amy Williams

University of California San Diego

Günter Lugmair

University of California San Francisco

Michael A. Wilson

University of California Santa Cruz

David Rubin 


\section{University of Colorado Boulder}

Bruce Jakosky

\section{University of Copenhagen}

Tonci Balic-Zunic, Jens Frydenvang, Jaqueline Kløvgaard Jensen, Kjartan Kinch, Asmus

Koefoed, Morten Bo Madsen, Susan Louise Svane Stipp

University of Guelph

Nick Boyd, John L. Campbell, Ralf Gellert, Glynis Perrett, Irina Pradler, Scott

VanBommel

University of Hawai'i at Manoa

Samantha Jacob, Tobias Owen, Scott Rowland

University of Helsinki

Evgeny Atlaskin, Hannu Savijärvi

University of Kiel

Eckart Boehm, Stephan Böttcher, Sönke Burmeister, Jingnan Guo, Jan Köhler, César

Martín García, Reinhold Mueller-Mellin, Robert Wimmer-Schweingruber

University of Leicester

John C. Bridges

University of Maryland

Timothy McConnochie

University of Maryland Baltimore County

Mehdi Benna, Heather Franz

University of Maryland College Park

Hannah Bower, Anna Brunner

University of Massachusetts

Hannah Blau, Thomas Boucher, Marco Carmosino

University of Michigan Ann Arbor

Sushil Atreya, Harvey Elliott, Douglas Halleaux, Nilton Rennó, Michael Wong

University of Minnesota

Robert Pepin

University of New Brunswick

Beverley Elliott, John Spray, Lucy Thompson

University of New Mexico

Suzanne Gordon, Horton Newsom, Ann Ollila, Joshua Williams

University of Queensland

Paulo Vasconcelos

University of Saskatchewan

Jennifer Bentz 


\section{University of Southern California (USC)}

Kenneth Nealson, Radu Popa

University of Tennessee Knoxville

Linda C. Kah, Jeffrey Moersch, Christopher Tate

University of Texas at Austin

Mackenzie Day, Gary Kocurek

University of Washington Seattle

Bernard Hallet, Ronald Sletten

University of Western Ontario

Raymond Francis, Emily McCullough

University of Winnipeg

Ed Cloutis

Utrecht University

Inge Loes ten Kate

\section{Vernadsky Institute}

Ruslan Kuzmin

Washington University in St. Louis (WUSTL)

Raymond Arvidson, Abigail Fraeman, Daniel Scholes, Susan Slavney, Thomas Stein, Jennifer Ward

Western University

Jeffrey Berger

York University

John E. Moores 